La brujería en la narrativa histórica española contemporánea (desde 1970 hasta la actualidad)

Eva Lara Alberola

Universidad Católica de Valencia "San Vicente Mártir" (España) 



\title{
La brujería en la narrativa histórica española contemporánea (desde 1970 hasta la actualidad)
}

\section{Witchcraft in Contemporary Historical Spanish Narrative (until 1970 to the present time)}

\author{
Eva Lara Alberola ${ }^{1}$ \\ Universidad Católica de Valencia "San Vicente Mártir" (España) \\ eva.lara@ucv.es
}

Fecha de recepción: 1 de febrero de 2018

Fecha de aceptación: 5 de mayo de 2019

\begin{abstract}
Resumen
En el presente artículo nos proponemos dar un paso más en la indagación sobre la brujería en la literatura hispánica, abordando en esta ocasión la narrativa histórica española desde 1970 hasta nuestros días. Las novelas seleccionadas han sido Retrato de una bruja de Luis de Castresana; La herbolera de Toti Martínez de Lezea; Ars Magica de Nerea Riesco; Las maléficas de Mikel Azurmendi y Regreso a tu piel de Lus Gabás. En un trabajo en gran parte descriptivo, se presentarán estos cinco relatos, resaltando los aspectos más llamativos que tratan sobre la brujería y las tesis que se vierten sobre este fenómeno y sobre la caza de brujas. Por tanto, se facilita al lector una panorámica acerca de los textos que ahondan en esta temática y se muestra que, en la actualidad, sigue muy vigente el interés por estas prácticas y su persecución, debido a lo complejo y controvertido del asunto y al drama que se vivió en los siglos XV, XVI y XVII, y que estos escritores han querido reflejar. Palabras clave: Literatura hispánica; Novela histórica; Brujería; Caza de brujas
\end{abstract}

\section{Abstract}

This article attempts to take a further step towards the investigation of witchcraft in Hispanic literature, now dealing with the Spanish historical narrative from 1970 to the present day. The novels that have been selected for such purpose are Luis de

1 El presente trabajo se inscribe en las actividades del Proyecto de $\mathrm{I}+\mathrm{D}$ del Programa Estatal de Generación de Conocimiento (MCIU/FEDER) PGC2018-095757-B-I00: Magia, Épica e Historiografia Hispánicas: Relaciones Literarias y Nomológicas II, dirigido por el doctor Alberto Montaner Frutos. Eva Lara también forma parte del grupo de investigación de la Universidad Católica de Valencia "Humanidades digitales", dirigido por el doctor Juan Gomis Coloma. 
La brujería en la narrativa histórica española... - Eva Lara Alberola

Castresana's Retrato de una bruja, Toti Martinez de Lezea's La herbolera, Nerea Riesco's Ars Magica, Mikel Azurmendi 's Las maléficas and Luz Gabás' Regreso a tu piel. In this article, which is mainly descriptive, these four stories will be presented highlighting the most remarkable aspects dealing with witchcraft together with the theses given about this phenomenon and the witch hunt. Therefore, the reader is offered an overview of the texts that delve into this subject and shows that, today, the interest in these practices and their prosecution is still alive not only thanks to the complexity and controversy of this matter, but also due to the tragic events that took place in the 15 th, 16 th and 17 th centuries, which these writers have tried to reflect in their books.

Keywords: Hispanic literature; Historical novel; Witchcraft; Witch hunt

\section{INTRODUGCIÓN}

La frontera que separa los territorios de la historia y la literatura ha sido, pues, permeable a lo largo de los tiempos y, así -pese a la conocida distinción aristotélica de historia y poesía- se han producido frecuentes incursiones de un género en el otro: la savia de la historia vivifica la literatura, y viceversa, la literatura es una fuente -si bien indirecta o secundaria- para el conocimiento histórico. (Mata Indurain, 1995: 14)

Este artículo tiene como objetivo profundizar en las muestras más representativas de la novela histórica española ${ }^{2}$ en relación con un tema de gran interés: la brujería.

2 Antes de pasar adelante, es necesario realizar algunas puntualizaciones. La primera tiene que ver con el hecho de que historiografía y literatura tendrían más puntos en común de lo que a primera vista pudiera parecer. Tal y como afirma Emilio Ramón: "los objetivos de la literatura y los de la historiografía no se hallan tan distantes como muchos pretendían. La historia es más un proceso de adaptación de los datos según un tipo de narración y unos objetivos, por lo que no puede ser del todo verdadera ni del todo falsa. Las teorías discursivas recientes disuelven la distinción entre discurso realista y discurso ficcional basada en la presunción de una diferencia ontológica entre sus referentes respectivos, real e imaginario, a favor de acentuar su carácter común de aparatos semiológicos que producen significados mediante la sustitución sistemática de significados (contenidos conceptuales) por las entidades extradiscursivas que les sirven de referentes" (2007, p. 66). La denominada novela histórica puede asumir así un papel determinante, al constituir un punto de intersección entre literatura e historiografía. Para Lukács, la novela histórica es aquella en la que los personajes se ajustan psicológicamente a la época en la que se ambienta la trama y no a aquella en la que escribe el novelista (1966, p. 15). Mata Indurain considera fundamental: "para que una novela sea verdaderamente histórica debe reconstruir, o al menos intentar reconstruir, la época en que sitúa su acción" (1995, p. 16), pero se ha de tener en cuenta sobre todo que se está ante una obra ficcional, literaria, mezcla de invención y realidad, que convierte este tipo de textos en un género híbrido (1995, pp. 17-18). En este tipo de relatos, aquellos protagonizados por personas marginales, que se encuentran muy lejos de las grandes figuras históricas, podrían aportar una nueva visión sobre las realidades que se pretenden reflejar. Emilio Ramón lo expresa así: "La historia hoy en día privilegiada no es ya la mítica de las grandes hazañas, sino que hay una convicción cada vez 
Dado que hemos tenido la ocasión de ahondar, en otros momentos, en los textos que se interesan por este fenómeno, desde la Edad Media hasta los siglos XIX-XX, es decir, desde la Claudina de La Celestina de Fernando de Rojas hasta La dama de Urtubi de Pío Baroja, nos centraremos esta vez en los relatos históricos publicados desde 1970 hasta la actualidad.

Hemos escogido el año 1970 como punto de partida porque se trata del momento en que ve la luz Retrato de una bruja, de Luis de Castresana, obra que consideramos absolutamente esencial en el campo que estamos trabajando. De ahí que este texto marque el inicio del período en el que vamos a centrarnos. Durante el siglo XX otros escritos se han acercado a este motivo, como el ya mencionado de Baroja, de 1916, pero dado que dichas muestras son conocidas y se han estudiado en numerosas ocasiones, hemos decidido presentar al lector materiales más cercanos en el tiempo y apenas abordados. ${ }^{3}$

mayor de que las experiencias que se suelen llamar marginales, las que no formaban parte del canon de la historia, son las que más están transformando nuestra visión de la misma" (2007, p. 66). Este hecho se va a observar en el tipo de narrativa que nos ocupa, puesto que no hemos de pensar que la novela histórica es solo la protagonizada por grandes personalidades de la historia, sino que pueden ser ciudadanos completamente normales (actantes ficcionales que el autor usará como hilo conductor para mostrar como telón de fondo aquellos aspectos del momento histórico escogido que desea resaltar o sobre los que pretende reflexionar). Eso expone precisamente Emilio Ramón, basándose en los trabajos de Umberto Eco, al decir que los estudios históricos actuales toman como referencia a minorías para acercarse a los acontecimientos. La literatura se sumaría a esta tendencia y, además, aprovecharía estrategias como las distintas voces, los juegos del lenguaje, la capacidad de valerse del sentido común para enriquecer los discursos expertos y autobiográficos, y las enormes posibilidades que supone la construcción de una teoría de la subjetividad (2007, pp. 71-72). La literatura ofrece una oportunidad de aplicar otra mirada. Como nos dice David Lowenthal (1985), los mejores relatos históricos han llegado en ocasiones a través de las narraciones literarias ficcionalizadas. Además, tal y como aduce José Saramago, la novela histórica tiene mucho que ver con la revelación del mundo de las personas sencillas, en busca de sus identidades, frente a las historias oficiales (1998, p. 26).

3 Hay otra obra, Las criaturas saturnianas, de Ramón J. Sender, de 1968, que se puede catalogar como novela histórica en tanto la protagonista es una figura como Lizaveta Tarakanova, que se proclamó hija de Isabel I de Rusia y, por tanto, aspirante el trono. Sender rectifica en su escrito la historia (Uceda, 1992, pp. 191-192) y transforma al personaje y sus andanzas, modifica su fecha de muerte y otros detalles. Tarakanova entra en contacto en este libro con Giuseppe Balsamo, conde de Cagliostro, que fue un famoso mago y ocultista muy famoso en la decimoctava centuria. Así lo mágico penetra en la novela con fuerza. En referencia a lo que nos puede interesar en este artículo, en los capítulos X-XII sobre todo, Lizaveta y el conde Cagliostro acuden al aquelarre de Zugarramurdi. La acción se sitúa en el siglo XVIII y no vemos que exista un afán de ajustarse a la realidad en la presentación del fenómeno que nos ocupa. La brujería se refleja como una práctica real, un culto al dios cabra Pan, una corriente satanista que se plasma de manera absolutamente surrealista. Aunque al presentar la brujería como una religión pagana el autor remite a las tesis de Margaret Murray (1921 y 1931) que veremos más adelante, no existe en Sender el afán de presentar esto como una teoría que permita explicar la naturaleza de esta ramificación vulgar de la magia. Ni siquiera es esta práctica el eje de la novela, sino solo un modo de mostrar España como un país irracional, repleto de dementes. Se combinan los típicos elementos del conventículo con otros que añade este escritor, como un macho cabrío que no es más que un humano disfrazado, el recitado de fórmulas en latín y otras disparatadas y 
La brujería en la narrativa histórica española... - Eva Lara Alberola

Nuestra finalidad es realizar una selección de textos, de entre los que ofrece el panorama editorial, y proceder a un análisis que atenderá a los aspectos destacados con respecto a la brujería y qué tesis se defienden sobre la naturaleza de este fenómeno y la caza de brujas, pues los autores siempre plasman sus conjeturas acerca de la brujería, y estas cuestiones resultan de gran interés.

Tras una minuciosa indagación, que nos ha puesto sobre la pista de diferentes materiales de diversos géneros, los títulos escogidos, por ajustarse a nuestros criterios, ${ }^{4}$ son: Retrato de una bruja de Luis de Castresana (1970), La herbolera de Toti Martínez de Lezea (2000), Ars Magica de Nerea Riesco (2007), Las maléficas de Mikel Azurmendi (2012) y Regreso a tu piel de Luz Gabás (2014). ${ }^{5}$ Todas ellas pueden encuadrarse en la narrativa histórica. ${ }^{6}$ Dejamos fuera de nuestra panorámica algunos textos de auto-edición, que no reúnen los requisitos mínimos para ser tratados en nuestro estudio. Se trata de Las brujas de Fernando Claudín (no se indica

sin sentido, y la asistencia de los que se hacen llamar nigromantes y que manejan sesudos libros (nunca se creyó que participaran magos cultos en estas reuniones brujeriles). Se da una mezcolanza que aleja este sabbat de cualquier aspiración realista. De ahí que este texto no forme parte de nuestro elenco.

4 El primer criterio es, desde luego, el temático; en los libros escogidos la brujería ha de poseer un papel fundamental o, al menos, una relevancia que indique el interés del autor por este asunto. El segundo criterio es el de género, de ahí que el drama quede fuera de nuestro elenco; es cierto que el teatro proporciona igualmente una materia prima muy aprovechable que debe ser explotada, pero se abordará en otros trabajos. Del mismo modo, la novela fantástica y la de terror no podían incluirse en el estudio, dado que el concepto de brujería está muy difuminado y, sobre todo en el primer género, no se respetan las convenciones acerca del fenómeno que nos ocupa, ni desde un punto de vista antropológico ni histórico. Nuestra pretensión era acercarnos a la brujería desde una perspectiva realista, pues esta es la que posibilita que los escritores viertan sus propias tesis al respecto. Por ello, se ha optado por la narrativa histórica. El tercer criterio, una vez determinado que la obra que iniciaría el recorrido sería Retrato de una bruja, es el temporal, marcando un período que va desde 1970 hasta nuestros días. Por último, un criterio imprescindible es el de calidad, dado que se pueden encontrar textos que cumplen el resto de requisitos, pero que, al ser novelas de auto-edición, no reúnen las condiciones formales (literariamente hablando) exigibles. El listado que vamos a manejar es el resultado de la aplicación de todos estos criterios.

5 Es muy importante aclarar que estas novelas recrean algún aspecto de la brujería, no solo de la hechicería (esta rama mágica puede estar también presente). Esta última no ha de confundirse con la primera. La hechicería es una de las ramas de la magia vulgar en la que hay alguna clase de trato diabólico, que puede ser más o menos explícito, cuya finalidad es conseguir influir en la realidad circundante, para amoldarla a los deseos del oficiante o de los clientes, ya que solía ejercerse como oficio. La hechicería se aprende, porque implica el dominio de una técnica; en cambio, la brujería es muy distinta, dado que, en su vertiente popular, constituiría la capacidad innata de causar mal en el otro, y llevaría aparejadas algunas costumbres malsanas como el infanticidio y el vampirismo; y en su dimensión canónico-teológica, implicaría un pacto manifiesto con el demonio, la pertenencia a una comunidad diabólica y la participación en los conventículos, además de que se mantendrían crímenes como los ya enunciados y se añadirían otros nuevos (véase Montaner y Lara, 2014, pp. 93-97).

6 Teniendo en cuenta, claro está, que como Emilio Ramón apunta, existen narraciones con distintos niveles de historicidad (2007, pp. 82-90). 
Revista de Humanidades, 37 (2019).p. 35-72. ISSN 1130-5029

año, probablemente 2015-2016) $;^{7}$ y El abogado de las brujas... el inquisidor de Elena Rojas (2015). ${ }^{8}$ Lo mismo sucede con Diario de una bruja (2013) de Amparo Fernández, editado por Palibrio. ${ }^{9}$

Los autores de las obras que vamos a trabajar son vascos u oscenses; en concreto son vascos Luis de Castresana, Toti Martínez de Lezea, Nerea Riesco y Mikel Azurmendi. La razón de ello es que los brotes de brujería proliferaron en el norte de España, y muy especialmente en Navarra y el País Vasco. De ahí que escritores de tal procedencia se hayan interesado por este fenómeno y por tratar de explicar lo sucedido, aportando sus particulares puntos de vista a través de la ficción histórica. Por otra parte, Luz Gabás es oscense y la acción de sus relatos se ubica en el Pirineo de tal territorio. Hay que tener en cuenta que todo el Pirineo, ya fuera navarro, aragonés o catalán, estuvo afectado por la creencia en la brujería y la caza de las presuntas personas implicadas en dicho crimen (Serra, 1994; Gari, 2010; Castel, 2013).

En el apartado siguiente, ahondaremos en los títulos escogidos, de manera sucinta, pues resulta imprescindible realizar algunas aclaraciones sobre el argumento de las obras escogidas, con el fin de mostrar cómo cuadra en los mismos la temática que nos ocupa. En ese sentido, en el presente estudio se combinará el trabajo descriptivo con el analítico, pues resulta crucial un primer acercamiento a las obras del elenco antes de poder llegar a conclusiones sobre el modo en que se enfoca el tema abordado. Nuestro objetivo final es ofrecer una panorámica al lector acerca de las narraciones que destacan en novela histórica (muchas veces combinada con otros géneros) sobre el motivo de la brujería. Si existe un interés que siempre persiste en lo brujeril, es porque este asunto continúa llamando la atención de autores y de lectores. De los primeros en tanto todavía prevalece un alto grado de misterio en torno a este fenómeno y se puede jugar con ese elemento; además, hay una tendencia

7 Fernando Claudín escribe una novela histórica con multitud de incorrecciones, hasta el punto de situar una caza de brujas en Urdax y Zugarramurdi en 1485 y de resaltar el Malleus Maleficarum cuando este texto no vio la luz hasta 1486. Claro está que nos hallamos ante una novela, no ante una crónica, pero existen otros fallos que no tienen que ver ya con los datos históricos. La acción no está bien construida. Se vuelca multitud de información de la relación del Auto de Fe de Logroño de 1610 editada por Mongastón y se utiliza el suceso narrado por Fray Prudencio de Sandoval acerca de las brujas navarras, en el cual habría participado el inquisidor Avellaneda, al que en este relato se convierte en inquisidor disidente, papel desempeñado históricamente por Alonso de Salazar y Frías. La combinación, por otra parte, de personajes históricos con otros inventados sin mucho sentido convierte este texto en una confusión constante.

8 En esta novela se reconstruye, punto por punto, todo lo acaecido en Zugarramurdi que conduce al Auto de Fe de 1610, y la histeria que se extiende tras el mismo. Se hace con una documentación limitada, con personajes más bien planos, y con un lenguaje deficiente.

9 Es una novela mística inverosímil en cuanto al papel de la mujer y a la brujería en sí. Se detiene en un culto femenino pre-cristiano que se hace coincidir con este fenómeno y abundan los elementos fantásticos que apartan a esta obra de la narrativa histórica, aunque se hace referencia a algún personaje o suceso histórico. 
muy acentuada a utilizar la narrativa para verter distintas opiniones y teorías sobre la brujería y la caza de brujas. De los segundos, porque lo mágico resulta atractivo, sobre todo cuando, al margen del género fantástico, se aborda desde un punto antropológico e histórico, tratando de dar respuesta a los grandes interrogantes que siempre se han planteado con respecto a lo oculto y esotérico.

No volveremos sobre lo ya expuesto en tantos y tantos manuales y artículos sobre la naturaleza de la brujería y su terrible persecución. Aprovecharemos, eso sí, las referencias de interés recogidas en las novelas para realizar apuntes, matizaciones y aclaraciones. Pero antes de seguir adelante, sí nos gustaría realizar una síntesis muy esquemática acerca de las principales teorías que se han barajado sobre este asunto. De este modo, podremos ir conectando las obras analizadas con estas hipótesis.

Norman Cohn (1980) determina que han existido varias líneas de interpretación: a) la que argumentaba que las brujas existieron aunque no como se reflejan en los procesos, sino que las creencias populares habrían contribuido a la formación del estereotipo (Tartarotti y los hermanos Grimm); b) la que avanzaba desde la consideración de la brujería como una religión natural pagana (Karl Ernst Jarcke y Franz Josef Mone) hasta la idea de la pervivencia de una religión precristiana que rendía culto a un dios de la fertilidad, defendida por Margarret Murray, pasando por un estado intermedio representado por Jules Michelet, quien hablaba de una protesta de los siervos contra el orden establecido y del sabbat como un festival de estos siervos; c) la que asegura que la brujería sí que existió tal y como fue descrita por los inquisidores y los procesos deben ser leídos literalmente (Montague Summers), y que evoluciona hacia la afirmación de la existencia de una religión anticristiana organizada, como protesta contra la religión oficial y una forma de rebelión social, de modo que los sabbats habrían tenido lugar (Jeffrey Russell); d) otra tesis apuesta por el hecho de que el estereotipo se inició como resultado de la campaña contra el catarismo y, según Cohn, esto sería invención de Lamothe-Langon; e) habría otra vía que tomaría como base el maleficium, que es la defendida por el propio Cohn, que se fusionaría con otras ideas, como la servidumbre al diablo, la mujer que vuela y comete crímenes y la sociedad secreta que celebra reuniones.

Gustav Henningsen (1983, pp. 67-68, p. 100, pp. 119-120, p. 196) también extrae interesantes conclusiones a partir de su investigación, aunque se aplica exclusivamente al proceso que condujo al Auto de Fe de Logroño de 1610 y a sus repercusiones, así como a la acción del inquisidor Alonso de Salazar y Frías, responsable de que terminara toda aquella locura brujeril. Este especialista determina que la brujería nunca existió, pero sí las confesiones y los testimonios varios al respecto, por un lavado de cerebro al que se sometía a los presuntos culpables, sobre una base común local de creencias y cuentos populares. Por tanto, la fantasía jugó un papel fundamental y la inquisición realizó una extraordinaria construcción tomando como base esas confesiones delirantes. Otra parte de tal manipulación se operaría desde el púlpito y alcanzaría a todos los vecinos de las aldeas y, especialmente, a 
los niños. Todo esto condujo a la convulsión social en diversos lugares del norte de España y a lo que este autor ha llamado "epidemia onírica" masiva.

Ginzburg (1990) se opone a Norman Cohn (1980), para quien el sabbat es una elaboración moderna, y apuesta por la presencia de este elemento en la cultura popular. De hecho, conecta el conventículo con la creencia en los Benandanti de Friulia.

Robert Rowland (1998) expone, por su parte, en qué consiste la corriente narratológica de interpretación de la brujería, enriqueciendo lo aportado por Cohn (1980), pues para él las confesiones de los brujos y brujas no son más que relatos que presentan una estructura muy determinada y, conforme avanzan los siglos XVI y XVII, las narraciones son cada vez más elaboradas y estereotipadas. Estas teorías permiten una aplicación cada vez mayor de la filología al estudio de la brujería.

Muchembled (2004) completa este panorama con algunas otras cuestiones: la caza de brujas sería un episodio de la conquista de Europa por las fuerzas de la ley y el orden y de ello se deduce que el sabbat es únicamente una invención de los teólogos cuyas ideas gobernaron la imaginación de las élites; todo esto sobre la base de la tradición en la persecución de ciertos grupos heréticos. En consecuencia, el conventículo es un concepto ajeno a los campesinos y todo dependerá de si las comunidades rurales aceptan o no el mito del satanismo.

Clark (2004) suma algunas líneas más a las ya expuestas: a) los estudios interdisciplinares permiten nuevos avances en este campo, como el operado por autores como Alan Macfarlane, Keith Thomas, Erik Midelfort, y más tarde Robin Briggs y Malcolm Gaskill, quienes consideran las acusaciones de brujería como un barómetro para medir las relaciones interpersonales y las tensiones producidas por las transformaciones sociales y los cambios religiosos; b) desde el feminismo se aboga por la misoginia y la idea de patriarcado como detonante para la persecución de la brujería; c) la historia cultural establece un nuevo modo de leer la demonología y se concibe este fenómeno como una narración cultural, como hacen Marion Gibson, Francis Dolan o Alison Rowlands, prestando más atención a los textos; d) también el psicoanálisis se preocupa por este asunto (Lyndal Roper y Deborah Willis), por los elementos perturbadores e irracionales de la fantasía de la brujería.

A todas estas tesis, habría que añadir otras que no se pueden obviar, como la de Faggin (1959), que ve a la bruja como algo necesario para demostrar la verdad demonológica, a lo que habría que sumar los cultos paganos, la histeria colectiva, la sexualidad reprimida y el uso de alucinógenos; la de Caro Baroja (1966), que parte de la teoría de la magia y hace también referencia a cultos antiguos, de modo que toma como base la magia antigua femenina para la posterior brujería, reinterpretado todo ello por el Cristianismo, también habla de folklore: mitos y leyendas, y añade la demonolatría; la de Konning (1975), que aboga por la brujería como liberación sexual; la de expertos como Donovan (1978), Levack (1995) y Tausiet (1997, 1998, 
2000, 2004), que ven la hechicería como base de la brujería y esta última como la búsqueda de un chivo expiatorio; la de Jiménez del Oso (1995), que ve en la brujería un montaje para eliminar lo que no interesa; la corriente de estudio que parte de la medicina y que podemos encontrar en Gari (1987), Becerra (2004) o Díaz-Rosales (2011), en referencia al uso de drogas en la brujería; o desde la psiquiatría en López Ibor (1978), etc.

Como vemos, son numerosísimas las hipótesis existentes, unas con más fundamento que otras. Si un tema como el que trabajamos ha podido dar lugar a tan amplio debate y tantas corrientes y escuelas de estudio (y no hemos presentado la totalidad de lo que se puede encontrar, sino solamente una selección para poder mostrar lo complejo del asunto), es porque da lugar a la controversia. Y todavía no se ha llegado a conclusiones absolutamente definitivas, sino que se sigue avanzando, gracias a la aplicación de cada vez más disciplinas, cosa que permite enriquecer el punto de vista del investigador. Este panorama es el que justifica el interés de los escritores de novela histórica, que pueden tener también algo que decir al respecto.

\section{RETRATO DE UNA BRUFA DE LUIS DE CASTRESANA}

El libro que inaugura nuestro estudio es Retrato de una bruja de Luis de Castresana y quedó finalista del Premio Planeta en 1970. Se trata de una novela histórica en la que la introspección resulta absolutamente fundamental, dado que el viaje de la protagonista, Ana, hacia la brujería es eminentemente interior. La obra plasma la complejidad del asunto que trata y es una de las más originales de cuantas vamos a abordar. Merecería la pena dedicar un pormenorizado análisis a esta narración, pero en un estudio como este resulta imposible extenderse. Además, ya se ha tratado detalladamente en otro trabajo dedicado por entero a este título (Lara Alberola, 2014).

Ana habita en una aldea vasco-navarra innominada ${ }^{10}$ de la cual se va a reflejar la vida cotidiana propia del siglo XVII, ya que aunque no se precisa el año en que arranca la acción, sabemos que recientemente ha tenido lugar el Auto de Fe de Logroño de 1610. No obstante, no nos hallamos ante un inminente brote de brujería, como puede esperar el lector. De hecho, el eje de la historia es la relación sentimental truncada entre Ana, hija de un noble de la aldea, y Martín, hijo de ferrón. Ambos se prometen en matrimonio antes de que el joven se marche a la corte para hacer fortuna, pero el muchacho solo regresará años después, casado con otra mujer. Ahí se encuentra el núcleo de la novela, en el vacío que se apoderará del corazón de Ana. Lo emocional es aquí la base para la construcción de la bruja.

10 Todos los relatos en que nos vamos a centrar se desarrollan en zonas rurales. Norman Cohn (1980, pp. 285-286) afirma que la idea de Joseph Hansen de que la creencia en la bruja nocturna se fomenta por las condiciones peculiares de la vida de la montaña posee vigencia. 
A esa base hay que añadir, como es evidente, unos ciertos conocimientos sobre la brujería, que llegan la población a través de un saludador que informa sobre los actos imputados a los brujos de Zugarramurdi. Además, la esposa del sacristán regresa de Bilbao con más noticias de este calibre y a esto se suman los sermones que sugestionan a los vecinos (52). Estos hechos resultan fundamentales. Tal y como Gustav Henningsen (1983, p. 340) expone, el inquisidor Alonso de Salazar y Frías reconocía que surgían brotes de brujería tan pronto como se comenzaba a hablar sobre brujas. La extinción de la histeria colectiva solo podría lograrse por una vía: el silencio. Por ello, las pláticas acerca de este asunto eran cruciales para que se expandiera la creencia en estos seres y en sus poderes, y pudieran darse las cadenas de acusaciones.

Ana posee unas referencias muy claras sobre lo que ciertas féminas podían realizar, en virtud de unos poderes fruto del pacto diabólico, ${ }^{11}$ por todos los relatos que ha escuchado desde la más tierna infancia, pues forman parte de su cultura y tradición:

Recordó algunas de las cosas que, desde niña, había oído atribuir a mujeres que, como Hilaria, tenían fama de poseer extraños dones o poderes. Se decía de ellas que eran brujas, que habían hecho un pacto con el Demonio ${ }^{12}$ y que tenían capacidad para hacer cosas incomprensibles que los demás seres humanos no podían ni siquiera sospechar. Se decía que esas mujeres no solamente podían obligar a un ausente a que se presentase ante la persona que la amaba, sino que tenían también poder para hacerse invisibles, interpretar el canto de las aves, hallar tesoros escondidos, no perecer por herida infligida por criatura mortal, librarse del granizo, caminar más de trescientas leguas en una sola noche, hacer que sus ollas guisasen solas, obligar a una persona a que durmiese tres noches y tres días sin despertar, quebrar el hierro, encantar serpientes, atraer la lluvia, volar por los aires recorriendo distancias portentosas, hacer que los peces de un río se reuniesen todos juntos en un mismo lugar, que de todos los huevos salieran pollos de color blanco, que una casa se incendiase y destruyese ella sola... ${ }^{13}$ (pp. 113-114)

11 Acerca de los conceptos básicos y de la diferenciación entre magia, hechicería y brujería, véase Montaner y Lara (2014, pp. 33-184). En este punto, merece la pena aclarar que lo que en la cita se plasma no tiene que ver con la brujería popular (bruja con poder innato para causar el mal, infanticida y chupasangre), sino con la interpretación canónico-teológica de la misma (bruja que adquiere sus poderes por un pacto diabólico), aunque dicha concepción de la brujería se difunda oralmente en las aldeas. En todo caso, puede haber una fusión de los elementos más tradicionales con la idea de pacto demoníaco. Para ahondar en la retroalimentación entre lo culto y popular en relación con esta temática, véase Lara Alberola, 2015 y 2016.

12 Como bien señala Henningsen (1983, p. 348), el contenido demonológico no fue importante en la brujería popular; es más, se transformó en cuentos y leyendas durante los períodos de normalidad, por eso hacía falta un nuevo adoctrinamiento.

13 Este tipo de noticias se podían encontrar en las misceláneas, como el Jardín de flores curiosas de Antonio de Torquemada (1570). También se difundían noticias como estas en relaciones de sucesos, que en España no abundan en referencia a cuestiones mágicas, aunque se pueden encontrar panfletos 
Se destacan creencias relacionadas con el trato demoníaco, pero apenas se menciona el maleficio y no se alude a las asambleas. El saludador sí añade todas las cuestiones leídas durante el Auto de 1610, que hacían referencia al aquelarre. Y esta visión se completaría con las palabras del sacerdote, a partir de sus lecturas de los principales tratados sobre el asunto.

Además, ya ha habido una persona acusada en el pueblo, Visitación, que será castigada, pero no ejecutada. El padre Melchor, buen conocedor de la tratadística, no deja pasar el caso, mientras que el Alcalde Perea no ve en ella más que a una mujer trastornada. La conjunción de estos dos puntos de vista da como fruto la moderación, de manera que se sigue la estela dejada por Alonso de Salazar y Frías, el inquisidor disidente del proceso de Logroño, que dudaba de la veracidad de todas las confesiones de los reos. ${ }^{14}$ De ahí que la situación no conduzca a ningún brote de histeria ni a ninguna persecución masiva (pp. 58-60).

La desesperación que sufre Ana la lleva a buscar soluciones que escapan a la ortodoxia. Primero se refugia en Ceferina, que posee algunos toscos conocimientos hechiceriles, pero nada de lo ejecutado obtiene resultado (pp. 96-97). Por ello, es conducida por su aya al tabuco de Hilaria, curandera con fama de bruja. Hilaria encarna perfectamente el arquetipo brujeril:

Era una estancia destartalada y espaciosa, enrarecida por el humo de la chimenea. Ardían fatigosamente unas leñas verdes, húmedas, sobre las que se hallaba una olla de hierro. Nada más aspirar aquella atmósfera, impregnada de un olor acre, Ana sintió un regusto amargo en la garganta; [...] quedó inmóvil mirando a la mujer que se inclinaba ante la chimenea, de espaldas a la puerta, y que con una delgada vara parecía agitar el contenido de la olla. (p. 105)

La anciana parece representar un papel sobre el escenario más adecuado: una destartalada casa en el bosque, una vida en aislamiento, la compañía de un sapo y un búho, multitud de ingredientes variopintos, el caldero hirviendo en el fuego... (pp. 105-110). Estas descripciones remiten a una brujería tradicional que vive en el imaginario colectivo, al margen de su interpretación canónico-teológica. Pedrosa (2002, p. 74) define a la bruja como la mujer poseedora de poderes innatos con los que realiza agresiones mágicas elementales. A esa idea básica hay que sumar ciertos elementos, como el vuelo, el infanticidio y el vampirismo y, posteriormente, los aspectos aportados por la tratadística (Montaner, 2014). Lo que no cuadra en esta estampa es que Hilaria posea libros de magia, pues no se corresponde con el estereotipo.

sobre el Auto de Fe de Logroño de 1610: el editado por Juan de Mongastón en Logroño en 1611, y el redactado por Luis de Fonseca y publicado por Juan Bautista Varesio en Burgos en el mismo año.

14 Para profundizar en las acciones de este inquisidor y en el papel determinante que desempeñó para terminar con la persecución, véase Henninsen (1983). 
Y Ana está dispuesta a entrar en un terreno peligroso para conseguir lo que quiere, a Martín. Hilaria comienza por algunos remedios de magia amatoria, para atraer al amante ausente durante la noche, haciendo uso de un unto que el lector sabe estupefaciente, ${ }^{15}$ pero la experiencia onírica no satisface a Ana, pues siempre despierta sola (pp. 136-137) y, además, descubre que él se ha unido a otra mujer.

Cuando el amor se convierta en odio, Ana emprenderá un camino sin retorno, se convertirá en aprendiz de la vieja, se iniciará en la secta y se transformará lentamente, desde el interior hacia el exterior. Hilaria la ayuda a dar el gran paso:

— Te concederá cuanto le solicites — siguió diciendo—. Me ha pedido... me ha pedido que vayas a verle el día del Gran Sabat.

La mirada de la anciana la envolvió como una red.

-Yo ya te ayudaré a hacer el gran viaje. Será un gran momento para ti, Ana. Adquirirás fuerza, poder, te sentirás libre. Sí, Ana, créeme: serás tan fuerte y tan libre que nadie podrá causarte dolor alguno. Se acabarán para ti las vacilaciones, los titubeos, los interrogantes, las dudas. Te desprenderás para siempre de las pasiones, de las humillaciones y las angustias humanas. Quieres ser libre y fuerte, ¿verdad? ¿Quieres ser libre y poderosa, y que ningún ser humano pueda hacerte sufrir? Dime: ¿es eso lo que quieres?

- Sí — pronunció Ana.

Fue como un juramento, como un pacto. (p. 149)

El pacto, en realidad, se da entre Ana y una parte de sí misma. Para ella, no obstante, el trato demoníaco será real y también el vuelo: "Toda ella era pura ingravidez, pura incorporeidad. Sin embargo, notaba intensa y profundamente el peso de identidad personal, el peso de su mismidad" (p. 166), o sus relaciones carnales con Lucifer. El conventículo se recrea según la imagen mental que estas mujeres poseen del mismo, alentadas por el modo en que lo va explicando Hilaria en el momento de la partida (pp. 164-165), a imitación de lo contado sobre el de Zugarramurdi. Y cuando llegue el momento de que Satán le conceda una petición, solicitará la muerte de doña Engracia, la madre de Martín, que fue quien lo instigó a casarse con otra mujer. Al poco tiempo, la mujer fallece, de manera fortuita, pero Ana se cree la responsable y siente un gran empoderamiento.

La transformación también se ha operado de cara a los vecinos. Además, cuando Hilaria muere, ella se convierte en su sucesora y genera en los aldeanos un respeto que nace del temor y que conducirá, finalmente, a la persecución. Quien es capaz de practicar la hechicería como un oficio al servicio de terceros (Ana es requerida constantemente) en una zona rural, puede también causar todo tipo de males.

15 Sobre el uso de estas sustancias en relación con la brujería, resulta interesante Becerra (2004). 
El linchamiento que conduce al desenlace de la obra tiene lugar cuando Martín regresa con su familia a la aldea, y Ana decide atentar contra su vida mediante un maleficio. Ante el ataque de los aldeanos, que la acusan de todas las desgracias que padecen, despertará su ansia de venganza: "-Mi amo, Señor de la Noche, destrózalos con tus podres - clamó-. [...] Reducid el pueblo a cenizas, que todo sea llanto y fuego. ¡Mi señor de la Noche, mi amo, escúchame, ayúdame!” (p. 235). Evidentemente, estas plegarias no obtienen respuesta, porque todo es una farsa. $\mathrm{La}$ lucidez regresa a su mente cuando se encuentra al borde de la muerte, fruto de las agresiones de los vecinos, y reconoce ante Ceferina que nunca asistieron al aquelarre, eso solo sucedió en su cabeza. Y aquí viene una de las reflexiones más llamativas del libro:

El aquelarre no era un lugar, sino otra cosa. El aquelarre era ella misma; algo que ella había creado en su mente, algo que ella había hecho surgir de su soledad y su angustia, de su dolor y su vacío. Recordó la mañana en que había ido a visitar a fray Miguel al convento y en que el fraile le había dicho que Desesperanza era uno de los nombres del demonio.... Recordó también las instrucciones de Hilaria ordenándole que no hablara con nadie de su vuelo hacia el aquelarre, ni de lo que allí sucedía. (pp. 239-240)

El lector comprende entonces que una mujer podría llegar a creerse bruja, al igual que Ana, siempre que se dieran unas circunstancias propicias de carácter contextual y existieran unas creencias previas, acompañadas de factores como un determinado estado emotivo o mental (López Ibor, 1976) ${ }^{16}$, la práctica de la sanación y la hechicería, y el uso de drogas. Externamente, la búsqueda de un chivo expiatorio a quien culpar de los males también sería determinante para completar la bidireccionalidad (Tausiet 2004a, pp. 46-47): ser bruja para una misma y también para los demás. Según Levack (1994, p. 296), habría mujeres que realmente intentarían iniciarse en la brujería y cerrar un pacto. Robert Rowland (1998, pp. 163164) afirma que muchas mujeres acusadas de brujería creían que ejecutaban aquello que en sus narraciones decían que hacían. De modo que lo que en un principio era una confesión de hechos ficticios se convertía en una firme convicción por parte de las implicadas. De ahí que Muchembled hablara de "peasant actor in these dramas" (1990, p. 140).

Hilaria sí era consciente del engaño, pero el temor que generaba le posibilitaba pasar de la inferioridad socia ${ }^{17}$ a la superioridad fruto del miedo ${ }^{18}$. Precisamente, $\mathrm{M}^{\mathrm{a}}$ Helena Sánchez Ortega (2004, p. 25) expone que: "Las mujeres [...] utilizaron la fe

16 En el Malleus Maleficarum se afirma: "Cuando las jóvenes, corrompidas y abandonadas por sus amantes, a los que se habían entregado bajo la promesa de matrimonio, se encuentran corrompidas y habiendo perdido su reputación. Entonces se entregan a cualquier acechanza diabólica. Bien por venganza para embrujar al amante o a la mujer con la que se ha casado, o bien maquinando otras cosas entregándose a todas las inmundicias" (Segunda Parte, Cuestión I, Capítulo I, pp. 217-218).

17 En relación con estas cuestiones de marginalidad, véase Val (2012, pp. 17-20).

18 Para ampliar todo lo aquí expresado, véase Lara Alberola (2014). 
de su entorno en sus supuestos poderes para establecer una muralla defensiva, una estrategia similar a la del inofensivo calamar que desprende su tinta cuando se siente atacado. El precio fue, con frecuencia, demasiado elevado.”.

El caso de Ana sería mucho más dramático, en tanto asume una nueva personalidad y la metamorfosis es completa.

\section{LA HERBOLERA DE TOTI MARTÍNEZ DE LEZEA}

Tras un llamativo vacío de treinta años, encontramos una novela de gran interés, La herbolera de Toti Martínez de Lezea (2000), una obra en la que ascendemos un peldaño en cuanto a información histórica con respecto al texto anterior, pues contextualiza perfectamente la acción, a pesar de que la trama principal es ficticia, tal y como hacía Castresana, pero se aportan más datos veraces.

Todo comienza con la persecución de los herejes de Durango, ${ }^{19}$ que años antes ya se había cobrado trece vidas, pero ahora vuelve a preocupar a las autoridades. Se trata de los seguidores de dos frailes franciscanos, uno de ellos Alonso de Mella, apostados en una pequeña casa en Tabira. Predican la pobreza y critican que la Iglesia atesore riquezas, entre otras cosas. También se les acusa, como había sucedido con otras herejías (Lara Alberola 2010, pp. 68-69) de "celebrar misas nocturnas seguidas de orgías, o hacer saltar de mano en mano un recién nacido sobre una hoguera hasta 'secarlo' para fabricar polvos con los que elaborar un bebedizo o quemarlo para mezclar sus cenizas con harina y elaborar hostias para sus misas sacrílegas" (p. 29). Del mismo modo, se sospecha que este grupo de personas puede querer alzarse en armas y fundar un Durango independiente (p. 31).

Con estas circunstancias comienza la andadura de Catalina de Goiena, perteneciente a una estirpe de mujeres con grandes conocimientos de plantas y hierbas, que habita en casa Goiena, en Arrazola. Además, ella ha heredado el don de su bisabuela, que le permite vaticinar quién vivirá y quién morirá. Para completar su formación como sanadora, su abuela Domenja la envía junto al físico don Diego de Olea, en Tabira. Igualmente, aprenderá el oficio de comadrona junto a Josefa.

Pronto se comienza a hablar de brujería en la merindad, primero en relación a los herejes, de los cuales se sospecha "que usen males artes para atraer a sus prosélitos" (p. 47); y posteriormente de forma independiente, materializada en las mujeres, cosa que apunta (p. 80) a un grado considerable de misoginia, que nace en múltiples ocasiones de las lecturas de tratados y obras similares por parte del visitador del Santo Oficio, Hernando Sánchez de Guinea, y sobre todo del escribano, Bartolomé Martínez de Unda. El Malleus Maleficarum cosechará gran éxito en este sentido (p.

19 En referencia a los herejes de Durango, véase Bazán (2007). 
120). ${ }^{20}$ Eso sí, por los estudios de que disponemos en la actualidad, todavía no queda totalmente claro que hubiera un brote de brujería en Durango, aunque existen varios testimonios que apuntan al suceso, que habría tenido lugar en 1507. No obstante, Bazán (p. 2011) concluye que es muy posible que entre los nombres que aporta Labayru de personas juzgadas en este lugar por herejía hubiera casos de brujería. Esta persecución se daría entre 1499 y $1508 .^{21}$

A estas consideraciones intelectuales, les servirán de base las creencias tradicionales. Existe, aunque no se profundice en ello, una brujería popular, que tiene que ver sobre todo con el maleficio (Cohn, 1980). Domenja explicará a Catalina sobre las mujeres de Goiena: "Nos temen. [...] Vivimos separadas del resto, raramente bajamos al pueblo y vamos poco a la iglesia. Tal vez por eso o porque hay gente que nos tiene envidia, otros que recuerdan a tu bisabuela y dicen que era una bruja, aunque olvidan las muchas veces que les curó un mal de hígado o una llaga purulenta." (p. 87).

Esa brujería tradicional apunta a la idea de que si una mujer es capaz de sanar también está en su mano dañar. Por tanto, nos situamos en el terreno del maleficio y del mal de ojo. ${ }^{22}$ Hay, sin embargo, otras creencias determinantes en esta historia, en conexión con la brujería: las paganas, que se concretan en el culto a la diosa Mari y que se intentan erradicar desde hace tiempo, para lograr la total cristianización del territorio. De hecho, las personas que todavía son fieles a dichos rituales se reúnen en el monte Anboto, en Jentilkoba, y sus asambleas guardan sospechosas similitudes con el conventículo brujeril (p. 165, pp. 193-194, pp. 207, pp. 262-263 y p. 307). Es necesario aclarar, llegados a este punto, que la tesis de que la brujería es en realidad la pervivencia de una religión pagana, interpretada bajo la luz del satanismo, enunciada principalmente por Margaret Murray (1921 y 1931), ${ }^{23}$ está totalmente superada, tal y como afirman Bazán (2011) y Aranzadi (1981) en referencia a la brujería vasca. De lo que sí se podría hablar es de un sincretismo religioso perceptible en la cultura popular y rural (Bazán, 2011, p. 199).

Por otra parte, Don Diego de Olea, el médico mentor de la protagonista, prevé muy bien lo que puede suceder y le otorga un carácter cíclico y universal:

De tiempo en tiempo las gentes sufren una especie de ataque colectivo y achacan todos los males a las fuerzas infernales que dominan la tierra, las plagas, las tempestades, las sequías. [...] Buscan chivos expiatorios para inmolar como lo hicieran los paganos cuando el mundo estuvo en tinieblas. Unas veces es a los judíos a los que temen y acusan de crímenes horribles; otras son los herejes. (p. 99)

20 Conviente destacar la diferenciación que, a nivel intelectual, se realiza entre la magia culta y la popular. La culta estaría permitida y será loada y practicada por Martínez de Unda (118)

21 Véase también lo afirmado por Reguera (2005, pp. 251-252), Cáseda (2007, pp. 307-308) y Gari (2010, p. 338).

22 Sobre el aojamiento brujeril, véase Tausiet (2004b).

23 En España se editan en 1978 y 1985 respectivamente. 
Y en esos herejes se incluye a las brujas. Sobre ellas indaga obsesivamente el escribano, y tras recibir noticias sobre casos allende los Pirineos, concluye que: "Las brujas existían, conocían las propiedades de las plantas, sabían de elixires, narcóticos y ponzoñas que utilizaban para asesinar a honrados ciudadanos, y alerta no perder de vista a curanderas, herboleras o sanadoras, que podían ser sanadoras disfrazadas" (p.232). Era muy fácil confundir a estas profesionales con brujas, aunque esto no llegaremos a comprobarlo en la trama, dado que habrá otros múltiples factores que entrarán en juego ante una acusación. De la misma manera, se hace ver el conflicto existente entre los médicos y las comadronas-herboleras (Cohn 1980, p. 313), pues Catalina es avisada e incluso multada por Martínez de Unda, por inmiscuirse en un terreno profesional que no es el suyo (p. 243).

Todo esto se halla aderezado por una serie de enfrentamientos sociales entre bandos y linajes del señorío. De modo que: "la encomienda de descubrir brujas o encantadores en tierras de vascos era como el aceite que flotaba en un barreño de agua, la capa visible, la excusa para llevar a cabo un exhaustivo examen de la situación política y social en ellas" (p. 249).

Definitivamente, el brote tiene lugar a causa de las acusaciones de una niña, Inés Ederra, de no más de diez años y que, supuestamente, es conducida a una reunión: "Dice que una vecina suya, la Marinatxo, la sacaba de la cama, untaba las plantas de los pies y de las manos, su cuello y espalda con un ungüento mágico y juntas volaban hasta las faldas del Anboto, donde tienen lugar las asambleas de las brujas" (p. 293). ${ }^{24}$ Y las describe de tal manera que a Catalina le recuerdan a las que se celebran en Jentilkoba. Así se intuye tras estas historias un sustrato de viejas leyendas vizcaínas que hablaban de la diosa Mari (p. 294).

La Marinatxo es vieja y pobre, y había tenido problemas con una vecina, por lo que se observa un perfil muy determinado: una fémina marginal y desprotegida, con un carácter taciturno (pp. 297-298). Una vez interrogada, comienza la cadena de delaciones, pues esta anciana acusa a otros vecinos y, finalmente, confiesa públicamente bajo presión:

Sí, soy bruja, utilizo cuerpos de niños muertos y testículos de gallos negros para elaborar mis pócimas, llevo toda la vida aojando a mis vecinos y ocasionando sus desgracias e incluso sus muertes y asisto a las reuniones en las que fornico en las que fornico con el propio Satanás. Y, ya que queréis saberlo, puedo llamar a las tormentas, los vientos escuchan mi voz, los rayos me obedecen y podría acabar con todos vosotros en un instante. (p. 323)

24 Gustav Henningsen (2010, pp. 119-122) proporciona varios testimonios de brujos juzgados en el Auto de Fe de Logroño de 1610 que decían haber sido iniciados en la secta desde niños y conducidos al aquelarre tras ser untados. Historias similares se plasman en la Relación que hizo don Lope de Isasti [...] acerca de las maléficas de Cantabria (1618) y se perpetúan en la tradición oral, dado que han sido recogidas muchas de ellas en diversas colecciones de leyendas, tanto en el País Vasco como en el Pirineo. 
Esta mujer es quemada en la hoguera, el resto de acusadas se libran de la muerte por falta de pruebas. Pero no termina ahí la historia, puesto que Martínez de Unda repara en la conexión que el Malleus realiza entre parteras y brujas (p. 332). ${ }^{25}$ Varias mujeres más serán acusadas y condenadas a pesar de las incoherencias en sus confesiones. Pronto Maritxiki, una de las comadronas, se convierte una rea más y da el nombre de Catalina, instigada por el escribano, que desea venganza porque la joven no ha cedido ante sus insinuaciones amorosas. Todas son ejecutadas, excepto la protagonista (aunque también confiesa a causa de la tortura), que está embarazada, y que es liberada por su tío y su abuelo mientras la trasladan hacia Calahorra. Sin embargo, muere al dar a luz a una niña que también será portadora del "don".

Múltiples son los factores que aquí se presentan y que, combinados entre ellos, podrían dar lugar a una persecución como la perpetrada en la novela.

\section{ARS MAGICA DE NEREA RIESCO}

Ars Magica de Nerea Riesco (2007) es un relato de mucha menor complejidad y profundidad. También presenta dos tramas ficticias pero bien contextualizadas, justo después del Auto de $\mathrm{Fe}$ de Logroño de $1610^{26}$ y durante el recorrido que realiza Alonso de Salazar y Frías (el tercer inquisidor, disidente, del proceso) en busca de pruebas sobre la existencia de la brujería. Comparecen igualmente otros personajes históricos que coexisten con figuras ficticias, como Rodrigo Calderón, el duque de Lerma y Bernardo de Sandoval y Rojas.

Hallamos dos acciones que discurren paralelas y en algún momento confluyen. Por una parte, encontramos la historia de Mayo de Labastide d'Armagnac y Ederra, su mentora, ambas mujeres curanderas y hechiceras, que practican una magia natural ensalzada frente a aquello que se cuenta de las brujas. La primera comienza la búsqueda de la segunda, desaparecida en Zugarramurdi, para descubrir finalmente que fue arrestada y trasladada a las cárceles de la Inquisición en Logroño, y murió en su celda. Y, por otro lado, está la trama protagonizada por Alonso de Salazar y Frías y su comitiva, entre quienes cobra relevancia el novicio Íñigo de Maestu. El inquisidor recorre todas las aldeas afectadas por brotes de brujería, tras la histeria despertada por el Auto de Fe. El hilo conductor de esta investigación será la muerte en extrañas circunstancias de Juana de Sauri, en Santesteban, que los aldeanos achacan a las brujas.

El viaje de esta comitiva, seguida muy de cerca siempre por Mayo, y sus experiencias ponen en conocimiento del lector los aspectos más llamativos de la brujería y el drama que se vivió en toda la zona visitada:

25 En relación con las parteras-brujas, véase Tausiet (1997).

26 Sobre la caza de brujas en Navarra y el país vasco, desde el siglo XVI hasta el XVII, con particular incidencia en el caso de Zugarramurdi, véanse Reguera (2012) y Usunáriz (2012). 
Revista de Humanidades, 37 (2019).p. 35-72. ISSN 1130-5029

Los padres reclamaron ayuda urgente porque sus niños volvían a confesar entre tembleques que, con nocturnidad y alevosía, mientras dormían plácidamente, las brujas se colaban por las ventanas para llevarlos al akelarre donde les adjudicaban una varita con la que pastorear el rebaño de los sapos ataviados de príncipes con vestiditos en miniatura que ellas reverenciaban como a ángeles de la guarda. Las gentes, aterradas, velaban noches enteras al lado de los críos embrujados para impedirles que se rindiesen al sueño, pero lo único que conseguían era que las brujas les buscasen las vueltas y, al llegar el nuevo día, cuando los mayores bajaban la guardia y los niños daban una cabezada, volvían a arrebatárselos. Los pequeños reconocían después entre hipidos y llantos haber estado con las brujas en el akelarre, aunque el sueño sólo los hubiese vencido por unos instantes (p. 33). ${ }^{27}$

Se refleja en este fragmento la cuestión de los niños-brujos, que provocaría una auténtica hecatombe en las pequeñas poblaciones, donde todos sospechaban de todos y cualquier persona podía ser acusada por estos infantes (Azurmendi 2013, pp. 57-58). La perplejidad y el temor se apoderaban así de los aldeanos:

Bastaba con que alguien hiciese una denuncia contra su vecino por haber blasfemado o por haberle hecho una confidencia que atentara contra algunos de los dogmas, para que el Santo Oficio decidiera apresarlo. [...] Los pobres se devanaban los sesos pensando de qué podrían estar acusados y, durante el tormento, acababan admitiendo mil aberraciones por ver si así los dejaban en paz. (p. 125)

No olvidemos que solo confesando se podía salvar la vida; negar las acusaciones podía conducir a la condena y, desde luego, hacía pasar al reo por la tortura. Este es el telón de fondo de esta novela, mucho más fácil de abordar que los relatos anteriores, pues se explica la realidad de la brujería solo en cuanto a algunos de los principios externos que influyeron en su propagación.

El desenlace de la trama protagonizada por Salazar es fruto de la resolución del misterio de Juana de Sauri:

De nada sirvió explicar que Juana había muerto ahogada porque nadie pudo comprender en qué se contradecía eso con la versión de Diego. Pero quizás la historia más tortuosa fue la que contó Madalen, la sastra, que decía haber visto a Juana sobrevolando el pueblo en una escoba junto a una bruja que llevaba sujeta por los pelos y que la empujó sin miramientos cuando estuvieron encima del río. Al parecer la bruja, tras comprobar que Juana se había ahogado, se marchó dibujando piruetas en el cielo, haciendo morisquetas burlonas con la boca y lanzando unas carcajadas que ponían los pelos de punta. (p. 178)

27 Esto es muy similar a lo reflejado en un ejemplo incluido en las relaciones del Auto de Fe editadas en Logroño y Burgos (relato 7 en Mongastón y 32 en Varesio, accesibles en la base de datos Ars Magica, a nuestro cargo, en el portal Parnaseo: http://parnaseo.uv.es/ArsMagica/ArsMagica.html) 
Aunque la sugestión de los vecinos les hace seguir pensando que todo ha sido obra de las brujas, por venganza. Para Salazar, si no hay pruebas que permitan afirmar la existencia de estas criaturas, es que todo se trata de una falacia. Y eso para el inquisidor será un problema, pues le conducirá a una crisis de fe:

A Salazar le hubiera gustado ver a alguna persona transformarse en cuervo, cerdo, gato o cualquier otra bestia delante de sus ojos, descubrir en el cielo nocturno a una mujer sobrevolando el pueblo montada en una escoba, examinar a alguno de esos sapos diabólicos de los que todo el mundo hablaba y que vigilaban a los mortales disfrazados con trajecitos de príncipe hechos a la medida de sus contrahechos organismos... pero eso no ocurrió. El diablo no había hecho acto de presencia por ninguna parte. (p. 179)

Para Riesco, al igual que para el resto de autores, la brujería no existe, es fruto de la histeria, aunque en el caso de este texto la obsesión viene producida por un complot. Las esferas de poder desean mantener el control de la población y veremos que antes de que Salazar llegara a los distintos pueblos, un grupo de individuos comandados por Rodrigo Calderón realizaba una actuación estelar que sembraba el terror, pues se hacían pasar por brujos. Todo apunta a que detrás de esto se encuentra el duque de Lerma, pero el lector descubrirá que quien mueve los hilos es el mismísimo Inquisidor General (pp. 412-414). Muchas veces se ha hablado, en referencia a la brujería, de conspiración (Bologne, 1997, p. 276; Muchembled, $1990)^{28}$, pero aquí Riesco inventa la suya propia.

Por otra parte, se añade:

Pero en los últimos tiempos, los inquisidores habían dejado bien claro que los dioses no cristianos eran enemigos de Jesucristo. Quienes los adoraban, entraban en conflicto directo con el Señor, ya que todas esas deidades no eran otra cosa que el mismísimo Satanás enmascarado para engañar a los mortales. [...] Cualquier práctica que tuviera que ver con ofrendas o loas a la diosa Mari o a otro de sus númenes boscosos sería considerada brujería. (p. 64)

Tras el plan de Sandoval y Rojas, estaba la preocupación por cristianizar las tierras en las que todavía quedaban vestigios de cultos antiguos. Se vierte así la tesis de que tras ciertas acusaciones de brujería podía haber una pervivencia de rituales paganos (Murray, 1921 y 1931).

\section{LAS MALÉFICAS DE MIKEL AZURMENDI}

Las maléficas de Mikel Azurmendi (2012) es la novela que precede a su monografía titulada Las brujas de Zugarramurdi (2013). Este autor es uno de los investigadores que se ha dedicado a estudiar la brujería vasca, en concreto los

28 En referencia a las tesis sobre la brujería, véase también Caro Baroja (1995). 
antecedentes del brote conducente al Auto de Fe de Logroño de 1610 y la histeria que sigue a este acontecimiento, erradicada en 1614. Esto es lo que trata en su relato y lo que analiza en su estudio de 2013. Este texto, por tanto, es fruto de una exhaustiva indagación, y superará a las narraciones anteriores en lo que a grado de información histórica se refiere, pues el mismo escritor, en una entrevista personal, nos aseguraba que en su narración "todo es real, si no veraz"29.

En todos los casos abordados estamos ante novelas de tesis, pero Las maléficas lo es a un mayor nivel, pues nos hallamos ante una reconstrucción que permite al autor introducir los datos recopilados durante su investigación y armar el rompecabezas, tratando de dar respuesta a todos los interrogantes planteados con respecto a un fenómeno tan controvertido.

Dada la creciente dificultad de poder analizar punto por punto esta obra, nos ceñiremos a ciertas cuestiones muy concretas. En primer lugar, aclararemos que la visión de la brujería que se presenta en todo momento es la que se deriva de la tratadística y los manuales de inquisidores. En ningún momento se habla de la base popular o tradicional y ni siquiera se mencionan las creencias ancestrales de los aldeanos como un elemento resaltable.

El narrador es el monje Martín Larraldecoa. Azurmendi dice haber conseguido de manos de Julio Caro Baroja en 1994 el manuscrito dejado por tal personaje. Martín, el único personaje ficticio, es el hilo conductor de la historia; se trata de un agote que asume la identidad de un vecino suyo y prospera, marchándose de su aldea, tras lo cual se verá envuelto en el suceso de las brujas de Zugarramurdi; es el principal responsable del cambio de actitud y conducta de Alonso de Salazar y Frías. El eje de la novela se articula en torno al recorrido que realiza este protagonista para indagar acerca de la brujería.

Podemos afirmar que Martín representa la razón, no cree en todas las patrañas sobre las brujas y considera que: "las autoridades nunca debían apoyarse en ciertas habladurías de la gente para impulsar en los tribunales la venganza" (p. 75), hay un lugar para la distensión de las querellas y es el recinto parroquial. Según palabras del monje: " $[\ldots]$ no tengo confianza en que la gente más instruida sea la más adecuada para opinar sobre las querellas populares y dictaminar sobre su nocividad" (p. 75). Así, al hilo de las reflexiones de Larralde y de sus descubrimientos, Azurmendi va desgranando todos los factores que considera esenciales en relación con este tema.

Todo comienza cuando, al otro lado de la frontera, de las primeras habladurías se pasa a la Comisión Parlamentaria de Burdeos el 17 de septiembre de 1605. Más tarde se alarma al propio rey Henri IV y este nombra una comisión el 10 de septiembre de

29 Entrevista concedida el 20/1/2016. 
1608 y pone a la cabeza a Jean d'Espagnet, acompañado por Pierre de Lancre. Los interrogatorios se efectuarán en el castillo de Sant Per. ${ }^{30}$

Martín, de hecho, halla al párroco de Hendaya muy influido por las instrucciones dejadas por d'Espagnet, aleccionando a los niños y llevándolos a pasar la noche a la iglesia. Este sacerdote, Aranceta, se da cuenta, gracias al protagonista, del daño que está causando: "[...] es usted, son sus sermones sobre el sabbat diabólico los que a un chaval cagado de miedo le han hecho urdir una amenaza demoniaca" (p. 106). Esto hace recapacitar a Aranceta sobre todo el proceso e incluso logra que solucione el problema y pida disculpas por los errores cometidos. Eso no impide que lo que está en marcha se concluya, pues varias personas serán ejecutadas, todo por las denuncias de niños o adolescentes. Cuando el protagonista se marcha hacia Navarra, en 1609, el mismo párroco forma ya parte de los acusados detenidos por De Lancre, y espera la muerte en Bayona por el delito de brujería.

Pronto cobra relevancia la figura de Jeanette d'Abadie, una pobre muchacha que describe con todo lujo de detalles el sabbat y parece haber sido aleccionada para hacerlo. De hecho, dice lo mismo que el vicario Ameztoy había ido refiriendo a los niños en la iglesia. El papel de los más pequeños iba a resultar fundamental. Los religiosos de varias aldeas actuaban de esta forma con los infantes, de modo que las acusaciones histéricas se sucedían. Como Martín expresa:

Sin embargo pude comprobar pronto que el secuestro nocturno de niños era, a menudo, un efecto de la insistente presión sobre De Lancre de los señores Urtubi y SantPer, señores sin influencia en esa franja norte del Labourd. [...] Esto podía hacerlo directamente Urtubi en connivencia con el señor de Sant-Per quien, por oficio, era juez de segunda instancia del país y en su castillo asistía como letrado a De Lancre. Esta reflexión [...] la fui hilvanando más tarde, cuando tuve conocimiento de las entrevistas que se estaban manteniendo en Urdax entre los emisarios de De Lancre y el inquisidor de Logroño, Valle Alvarado. (pp. 127-128)

30 Azurmendi (2013, pp. 32-39) explica que en San Juan de Luz se dan unos conflictos que resultan determinantes, pues son el detonante de la persecución en el Labourd. En esta población se encuentran dos facciones sociales, una en alza (comerciantes y menestrales enriquecidos con sus actividades marítimas, ya que habían sustituido su dedicación a la tierra por otras que les reportaban mayor beneficio) y otra en decadencia (nobleza rural representada por el señor de Urtubi y sus partidarios). La facción en alza había tomado el poder local y esto había acarreado enfrentamientos, saldados con unas primeras acusaciones de brujería contra mujeres relacionadas con Urtubi-Alzate. Esta información llega al Parlamento de Burdeos, pero finalmente se archiva. El siguiente movimiento, por venganza, se dará por parte de Urtubi-Alzate y llegará hasta el rey Henri IV, al que se avisa de la plaga de brujas que existe en el Labourd. El monarca envía a Jean d'Espagnet y Pierre de Lancre. A partir de ese momento, las acusaciones se dan de forma interesada por parte de la nobleza rural en declive. De Lancre ejecuta a más de 80 personas en el Labourd y, tras estos acontecimientos, las noticias arriban a nuestro país y la situación se va complicando. 
Revista de Humanidades, 37 (2019). p. 35-72. ISSN 1130-5029

Los párrocos poseerán también un papel fundamental en esta complicada red:

Las mozas, bien aleccionadas de antemano por las pláticas nocturnas del párroco, aseguraban haber visto lo que el juez quería que hubiesen visto merced a estudiadas preguntas dirigidas a pedir un sí o un no rotundos. De modo y manera que [...] esos sueños se transformaban, al más liviano toque de atención del juez, en una realidad eminentemente real. Así comenzaba una cadena de delaciones que volvían a hacer realidad viejos sueños infantiles, aspiraciones frustradas, envidias contenidas u odios familiares. (p. 129)

Una vez llegamos a Zugarramurdi, la clave parece estar en María de Xumeldegui, la muchacha que regresa a la aldea desde Francia. Su relato habría quedado en cuento maravilloso de no ser porque lo conectó con personas del entorno. "María Xumeldegui había ganado su apuesta narrativa, que en adelante quedó convertida en hecho eminentemente real" (p. 159). Para Labayen, vicario de Echalar, tenía que existir una fuente inductora en el comportamiento de esta muchacha y apunta nuevamente a Urtubi (p. 165).

Fray Felipe, el sacerdote de la aldea, opta por la confesión pública en la iglesia, pero, desgraciadamente, no queda ahí el asunto:

Las cosas hubiesen seguido en ese precario sitio de la paz aldeana que sabe sobreponerse con cordura a las dificultades de convivir, de no ser que el abad de Urdax hubiese impedido que las cosas volviesen a su sitio de siempre. En efecto, nada más realizar la reconciliación de Año Nuevo, deseoso el abad Aranibar de congraciarse con la Inquisición había informado en secreto de estos hechos al tribunal del Logroño solicitando una intervención inmediata. ${ }^{31}$ (p. 162)

Por otra parte, se añade la tesis de que en Zugarramurdi se habría castigado a las familias que habían aceptado a los agotes en matrimonio (p. 168) y Martín completa esta interesante información:

Mi hipótesis provisional era que la sensibilidad ante la humillación pudo haber llevado a esas cuatro irresolutas familias de pastores y agricultores [Goiburu-NabarrecoTellechea-Barrenechea] a repudiar la ominosa sujeción al convento. En esa hipótesis encajaba como en su horma la sospecha de Labayen acerca de un Urtubi interesado en propagar por doquier el incendio de la secta diabólica, en comandito con el abad premostratense, deseoso también de revancha contra cuantos se habían puesto a la cabeza de la desanexión, veinte años atrás. (p. 168)

Para Larralde todo es como una "tramoya montada por un artista" (p. 173), es como si asistiera a una representación. "Sin embargo traté de precisar lo que de específico había en esta otra representación trágica añadiendo que mucho de lo que ahora sucedía podía estar ya escrito en algún libreto oculto, pero que los personajes

31 Se hace referencia igualmente a las traducciones erróneas, cuestión de gran importancia resaltada por Azurmendi (2013, p. 138). 
de nuestro drama sufrían de verdad y serían sacrificados en su vida real" (p. 173). De hecho, los Inquisidores al principio están perplejos ante el asunto que el abad ha puesto en sus manos, pero pronto se convencen de que se enfrentan a una secta hereje (p. 220).

No obstante, como bien subraya Martín, no existen pruebas que respalden las acusaciones. Esto es lo que corroborará Alonso de Salazar y Frías, con quien nuestro protagonista entrará en contacto y con quien poseerá una cada vez más estrecha relación. Así plasma Larralde su parecer al respecto:

Solamente subrayo que nadie ha probado la veracidad de los supuestos maleficios, nadie ha recuperado los supuestos cadáveres de niños, nadie ha querido confirmar qué mieses concretas se hayan perdido o navíos de qué nombre se le hayan hundido a tal o cual armador en este o aquella fecha. Sin embargo todos ellos han comulgado en prisión. Son como somos los demás, pecadores que aman a Dios y quieren ir derechos al cielo. No veo al diablo en todo esto. [...] [Veo] A Inocencio VIII, los dominicos Institor y Sprenger, a los teólogos que necesitan del diablo para dar empaque a su reflexión. (pp. 248-249)

Antes del inicio de las persecuciones en el Labourd, los aldeanos no sabían nada de la brujería, todo lo habían aprendido de los sermones y conversaciones con aquellos que habían presenciado los juicios franceses (p. 279). Los predicadores habían tenido también una gran responsabilidad en la propagación del terror.

Todo esto lo descubre Martín en su recorrido, al igual que lo hace Salazar tras al Auto de Fe, cuando parte en busca de pruebas. El cambio de actitud de este tercer inquisidor será el núcleo de la novela y se dará gracias a la influencia del monje. Al final, durante el edicto de gracia, Salazar solo se topa con vacilaciones, retractaciones, torpezas, contradicciones e ingenuidades (p. 383).

Tras la intervención de Salazar ante la Suprema y el dictamen de este tribunal, y cuando se deja de hablar sobre brujería, esta se extingue:

El terror produce delirios [...] y los dimes y diretes entre vecinos, el resquemor y los odios hacen el resto. Pero la iglesia española está demostrando que puede deshacer el entuerto y corregirse. [...] Mas todo parece haberse amansado al desparecer De Lancre y mandarse guardar un silencio sepulcral sobre este asunto del diablo y sus secuaces, ¿no? (p. 402)

De este modo, termina Azurmendi de presentar sus tesis, que se engarzan de manera perfecta, para mostrar al lector una visión de los hechos magistralmente reconstruida. Esta novela de ficción histórica permite al autor llenar todos los huecos, cubrir todas las lagunas que quedaban en los estudios sobre este tema, y poner su interpretación del asunto a disposición de un lector mayoritario. La clave de esta obra está en que se han sabido conjugar distintos condicionantes en un esfuerzo por entender y explicar lo que pudo conducir a un Auto de Fe como el de Logroño en 1610. 


\section{REGRESO A TU PIEL DE LUZ GABÁS}

Por último, Regreso a tu piel (2014), de Luz Gabás, también opta por situar un proceso por brujería en el núcleo de la historia. De hecho, la autora explica en una nota, al final de la obra, que la idea parte del hallazgo, en 1980, por parte de Domingo Subías, párroco del pueblo pirenaico de Laspaúles, de unos documentos originales del antiguo Concejo (equivalente al ayuntamiento), del período 15761636. La mayor parte de la información contenida tiene que ver con los quehaceres cotidianos de los vecinos, pero hay dos páginas que llaman la atención porque se presenta un listado de mujeres ahorcadas por brujas en 1592. Ahí se cifraría el origen de la novela, sumando otro elemento esencial: las leyendas propias de la montaña de Turgón, en la comarca del Ribagorza, que alcanza los valles de Benasque, Isábena y Lierp, zona con la que tiene una relación muy cercana la escritora (Regreso a tu piel, "Nota de la autora", p. 507).

La novela, por tanto, reconstruye desde la ficción lo que podría haber sucedido para que se diera el ajusticiamiento de estas mujeres, y lo hace entrecruzando presente y pasado; a través del personaje de Brianda, que regresa al pueblo de su familia, Tiles, en el Pirineo oscense, tras sufrir una crisis nerviosa. Allí experimenta una serie de regresiones a finales del siglo XVI, a otra época y a otra vida. Su alter ego, Brianda de Anels, originalmente de la Casa Lubich, le permitirá conocer los convulsos momentos políticos y los enfrentamientos que se vivían en el lugar.

El otro gran eje del argumento es la historia de amor entre Brianda y el italiano Corso, tanto en el pasado, como en el presente, que es cuando se reencuentran tras centurias de separación. Acudimos a dos relaciones amorosas alejadas en el tiempo, la última solo fruto de la primera, truncada porque Brianda fue ahorcada por brujería y arrancada del lado de su marido y su hijo Johan. Antes de morir, la joven prometió que encontraría la manera de volver junto a su amado, de desafiar todas las leyes para poder regresar a su piel.

Todo en el texto comienza con unos inexplicables sueños, que la protagonista no puede explicar, pero que la angustian. Continúa con el descubrimiento, por parte de Neli, una wiccana afincada en Tiles, ${ }^{32}$ de unos papeles antiguos en la cómoda de nogal de la sacristía que está restaurando, anotaciones del Concejo de dicha población, en los que figura un listado de veinticuatro mujeres del valle presas y azotadas entre el 19 de febrero y el 2 de abril de 1592, y que perdieron la vida en distintas ejecuciones, entre el 4 de marzo y el 29 de abril del mismo año (p. 117). Mientras tanto, se da, además, el encuentro entre Brianda y un tal Corso, italiano, que está inmerso en la reconstrucción de la Casa Lubich, cosa que hace que los recuerdos se agolpen en la mente de la muchacha. Por último, Brianda sufre una regresión durante la cual parece que esté muerta. Es en ese momento cuando acude

32 Es decir, una bruja moderna, lo cual significa que practica una religión neo-pagana demoninada Wicca y basada en los presupuestos defendidos por Margarret Murray en 1921. 
a los acontecimientos más importantes de la vida de su antepasada: el prendimiento, la acusación y la ejecución.

La trama del pasado comienza en 1585 en Tiles y se resaltan desde un primer momento los enfrentamientos entre dos facciones: los partidarios del conde Fernando y los seguidores de Medardo, los rebeldes. A pesar de que los nobles de la zona, y más concretamente los de las tierras altas de Orrun (Ribagorza), han acudido al rey, Felipe II de España y I de Aragón, a trasladarle sus quejas, nada se ha hecho y las tensiones son cada vez mayores. Ese es el contexto en el que se debe situar la acción.

Brianda es hija y única heredera de uno de esos señores, Johan, de la Casa Lubich. En uno de los viajes que realiza junto a su progenitor, conoce a un soldado desertor de origen italiano, Corso, y entre ellos comienza una historia que parece imposible, pero que terminará en boda. Tras el asesinato de Johan por parte de sus enemigos, Elvira, madre de Brianda, contrae matrimonio con Jayme de Cuils, su amor de juventud, uno de los asesinos de Johan, que pasa a ser el nuevo señor de la casa y padre de un varón que será quien heredará todas las posesiones de la familia. La joven protagonista no puede perdonar la traición de su madre ni superar la muerte de su padre, y huye. Es entonces cuando se topa con Corso, malherido, al que creía fallecido en batalla, y lo conduce a Casa Anels. Esta es ahora propiedad del militar, pues tras ser acogido por Nunilo y su esposa durante un tiempo, fue para ellos como un hijo y Nunilo le legó todos sus bienes, antes de ser ajusticiado por sus detractores. En su nuevo hogar, Corso se recupera y se casa con Brianda. Poco después, tienen un hijo, el pequeño Johan, y su felicidad pronto se ve interrumpida.

El supuesto brote de brujería se propicia con los sermones de Fray Guillem, quien afirma que se ha desatado la cólera de Dios por el comportamiento de los aldeanos, y este hecho deja más espacio a la acción del diablo, criatura capaz de provocar infinitos males en el ganado, las cosechas, la salud humana... Pide a todos los presentes que estén atentos, prestos para desenmascarar al demonio y vigilantes ante las mujeres, más inclinadas a dejarse engañar por él (pp. 412-413). Así se va allanando el terreno para las futuras acusaciones. Ya decía Neli que "la sugestión es terrible [...]. Por culpa de ella han muerto miles de personas. Imagínate hace cuatrocientos años, sin luz. En cada sombra estaba la presencia del diablo" (p. 340).

Una vez esta clase de lecciones habían hecho mella en los aldeanos, se convoca el Concejo en la iglesia de Tiles para presentar unos estatutos de desafuero, argumentando: "nuestra situación es tan delicada que no podemos esperar a que la justicia ordinaria resuelva. [...] El retraso en la aplicación de sus sentencias es de sobra conocido. No podemos esperar más" (p. 419). Inmediatamente y como golpe de efecto, se presenta el testimonio de Alodia, una de las vecinas y esposa de Marquo, que estuvo prometido años antes a Brianda: "Estaba la criatura sana y buena y hace cuatro días amaneció muerta. [...] Tenía la punta de la nariz vuelta y pegada a la cara, la boquita abierta y en los pulsos marcas y pizcos de haber sido agarrada por alguien. [...] El día de antes mi hijo estaba bueno y las brujas me lo mataron por la noche" (p. 
Revista de Humanidades, 37 (2019). p. 35-72. ISSN 1130-5029

419). ${ }^{33}$ Esa palabra, "brujas", causa un gran revuelo en la iglesia, y se va a convertir en la auténtica clave de la situación que se está viviendo: todo es obra de las brujas. Y, como vemos, el infanticidio va a ser un puntal muy importante en este proceso.

María Tausiet ha sido quien mejor ha sabido captar este hecho:

Lo que importa por encima de todo es la opinión pública, principal dispensadora de la fama y el honor. La esfera de lo íntimo y lo privado, prácticamente reducida al hogar y al círculo familiar, quedaba asociada al mundo de las mujeres. Algunas de ellas, las brujas, desempeñaron un cometido todavía más arduo: cargar con el peso de lo inadmisible en un momento de creciente control ideológico. Las diversas traducciones del infanticidio $[\ldots]$ no hacían sino enmascarar bajo el lenguaje de la brujería un conflicto de muy difícil solución. (1998, p. 83)

Según los nuevos estatutos, para estos casos: "Contra tales delincuentes serán hábiles para testificar cualquier hombre o mujer, aunque sean consortes, consocios y conreos del mismo crimen, puesto que este crimen se perpetra ocultamente y con sugestión diabólica" (p. 420). Se van a dar todas las facilidades posibles para poder acusar. Y de repente todos los vecinos tienen algo que decir:

Corso escuchó que hablaban de enfermedades y angustias, de discusiones entre vecinos, de viejas que paseaban por la noche, de unos que hablaban mal de la Cuaresma, de las bulas y el clero, de otros que sin trabajar se encontraban el trabajo hecho y el pan abundante y caliente porque se lo había proporcionado el diablo, de cantos que escuchaban por la noche, de conocidos que se habían levantado por las mañanas llenos de pellizcos y moratones, del aumento de gatos negros en lugar de los comunes blancos y grises, de los continuos robos que sufrían, de niños que morían con el cuerpo lleno de cardenales, de personas que no olían a cristianas, de unas que habían rehusado ayudar a otras y luego habían abortado y de otras que se habían negado a hacer la señal de la cruz sobre la tierra junto al lavadero... (pp. 420-421).

Pere de Aiscle interviene para cuestionar que se conviertan unos vecinos en jueces de otros, pero Jayme de Cuils argumenta que tendrán la asistencia de Fray Guillem, se pondrán bajo la protección del rey y del obispo de Barbastro para actuar en su nombre (p. 421). El resultado final será, evidentemente, un linchamiento por parte de la justicia civil, no de la Inquisición, que no participa de este proceso; y la revuelta de unos aldeanos contra otros.

33 Leonor, esposa de Nunilo, más adelante dirá con respecto a estas afirmaciones: "Aldonsa me contó que una de las criadas de Alodia le había dicho que el niño había muerto asfixiado bajo sus pechos. Si no bebiera tanto vino estaría más alerta. ¡Vaya excusa ha buscado para explicar su insensatez" (423). Esto es precisamente lo que expone María Tausiet: la brujería como metáfora para explicar el infanticidio causado por descuidos, como el hecho de dormir con el bebé después de haber consumido bebidas alcohólicas (1998, p. 74). 
Tras estos primeros acontecimientos, Corso propone a Brianda que huyan lejos de allí y ella, aunque con reticencias, acepta, aunque no conseguirán ir muy lejos. La primera en ser prendida es su criada Cecilia, una gitana. Poco después, cuando todos los vecinos han sido convocados en la iglesia, se señala a otras mujeres, utilizando como medio a un saludador (séptimo hijo de una familia de solo varones que posee una gracia especial para obrar prodigios y reconocer brujas). Se trata de una estrategia bien meditada por parte de ciertas personas del pueblo, entre ellas Jayme de Cuils, sobre todo teniendo en cuenta que Brianda ha presentado un requerimiento ante el monarca para que le sea restituida su legítima herencia, la Casa Lubich. Si la muchacha muere, se termina el problema. Así que, como Corso sospecha, una de las personas escogidas por el saludador es Brianda.

La protagonista, además, es desnudada, para proceder a la búsqueda de la marca diabólica. ${ }^{34}$ Lo que se halla es la ausencia de vello en las axilas, lo cual resulta determinante como prueba de que es una servidora del diablo. ${ }^{35}$ La muchacha se mantiene firme en los interrogatorios, y siempre niega su pertenencia a la secta y su participación en los crímenes que le intentan imputar. Como evidencia, ya que no poseen su confesión, se toman los testimonios de otras personas, que ven un acto definitivo en el hecho de que Brianda tomara por sirvienta a una gitana; que su marido, un pobre soldado, terminara heredando Casa Anels, o que ella fuera capaz, en una situación límite, de matar a un lobo con sus propias manos. Se consideran pruebas concluyentes y se condena a Brianda a morir en la horca, a pesar de la sospecha de que puede estar embarazada (Corso comprueba que lo estaba al exhumar el cadáver para ver si esto era cierto). Otras muchas mujeres caerán y la locura solo terminará cuando lo haga la purga. María Tausiet ya decía que:

la enorme fuerza metafórica de la brujería sirvió de pretexto tanto a instituciones como individuos para la consecución de intereses muy diferentes. [...] las acusaciones maléficas lanzadas por unos vecinos contra otros no eran sino formas de enmascarar conflictos muy diversos, desde los puramente económicos, pasando por las difíciles relaciones interpersonales, hasta los que tenían lugar en el interior de la propia conciencia (1998, p. 62).

Luz Gabás, como ella misma también indica en su "Nota de la autora", intenta mostrar a un público no docto en estas cuestiones algunas particularidades de la brujería, como el hecho de que la mayor represión fue llevada a cabo por la justicia seglar y, en algunos lugares, los poderes locales se tomaron la justicia por su mano, como vemos en esta novela. Igualmente, una de las principales tesis planteadas en este escrito es que las persecuciones solían ser síntoma de las ansiedades propias de

34 Sobre las particularidades generales de esta marca y su relevancia tanto en el concepto de brujería como en su persecución, véanse Cohn (1980, p. 288), Levack (1995, p. 53), Delpech (1993), Foucault (1999, pp. 195-197), Muchembled (2004, p. 81) y Tausiet (2004a, pp. 45-61).

35 Precisamente, Pau Castel señala esta creencia, de ausencia de vello en axilas y/o pubis, como un antecedente del estigma demoníaco en la piel (2013, pp. 89-90). 
Revista de Humanidades, 37 (2019).p. 35-72. ISSN 1130-5029

momentos de transformación social (p. 508). Vemos, igualmente, que se utiliza la brujería como chivo expiatorio. No sin razón afirman Stewart y Strathern:

Históricamente, en contextos a escala reducida o al nivel de la comunidad, las habladurías hostiles sobre los vecinos que se derivan de incidentes concretos o de conflictos, desgracias, celos o rencor hacia la suerte de los demás provocaban acusaciones de brujería o hechicería. En estas habladurías de ámbito local influían mucho los rumores que circulaban libremente de unas comunidades a otras y que reflejaban cambios históricos mayores. Los juicios por brujería representan a confluencia de esos acontecimientos locales e interlocales que culminan en actos de expurgo o búsqueda de chivos expiatorios. $(2008$, p. 7$)$

Y no se pueden descuidar tampoco factores como los mitos o supersticiones regionales, ni la influencia de la predicación, que ponía en circulación la interpretación canónico-teológica de la brujería. Siempre ha de haber una conjunción de elementos para que se prenda la mecha de las hogueras o, como en este ejemplo, se tense la cuerda de las horcas.

\section{CONGLUSIONES}

En este trabajo, hemos ofrecido al lector un elenco de las novelas históricas más actuales que hacen de la brujería su tema central, y algunas puntualizaciones básicas acerca de los aspectos tratados en torno a dicho fenómeno. Todas las narraciones ubican la acción bien en Navarra y el País Vasco, bien en el Pirineo aragonés. En cuanto al momento histórico abordado, La herbolera y Regreso a tu piel optan por el siglo XVI y el resto por el siglo XVII, tomando el Auto de Fe de Logroño como un acontecimiento crucial. Todos los relatos abordan con complejidad y profundidad la brujería, solo Ars Magica simplifica los acontecimientos en comparación con el resto de textos; y también hay que tener en cuenta que Regreso a tu piel utiliza el descubrimiento de unos documentos sobre un proceso brujeril en 1592 para construir toda una historia de amor que desafía el tiempo. Por otro lado, destacaría Retrato de una bruja por el punto de vista psicológico que adopta, frente a la visión más histórica de Martínez de Lezea y Azurmendi.

Nos encontramos con un abanico de textos que presenta ricos matices, dado que se encuentran constantes en todos ellos, como el interés de los autores por reflejar acontecimientos históricos que tienen que ver con la brujería. La totalidad de ellos construyen la trama en torno a este fenómeno. Las disimilitudes vendrían representadas, sobre todo, por el grado de relevancia otorgado al tema en cuestión, pues en algunas obras, como la de Gabás, el espacio dedicado a esta temática no es tan amplio como en el resto de títulos, pero se aportan detalles ausentes en otros textos, como la relevancia del infanticidio o una mayor focalización en la brujería como purga. 
Todos los escritores toman la brujería como eje fundamental de sus escritos, en un intento de que sus novelas permitan reconstruir lo sucedido, como se intenta en Las maléficas de una forma clara y directa, y también en Regreso a tu piel, pero disponiendo de muy pocos datos en contraste con toda la documentación manejada por Azurmendi; o se idea un personaje similar a cualquiera que hubiera participado de los hechos, como en La herbolera; después están las tesis más sensacionalistas $\mathrm{y}$, por tanto, menos realistas, pues no debemos olvidar que estamos ante novelas y el desenlace no siempre se ciñe a un deseo de fidelidad histórica, como ocurre en Ars Magica; por último, sin olvidar nunca un telón de fondo que se ajusta a lo que en la época se podría encontrar, tenemos el intento de, a través de una figura ficticia, profundizar en los condicionantes psicológicos, abordando la cuestión desde la interioridad, como sucede en Retrato de una bruja.

En los textos abordados de forma general se ofrece una visión canónicoteológica de la brujería, de pacto diabólico y aquelarre, derivada de la tratadística, que se propaga por medio de los sermones, pero también a través de las noticias que circulan tras los procesos y ejecuciones. La dimensión popular se plasma en menor medida, aunque se deriva de la presentación de Hilaria en Retrato de una bruja y de las referencias al maleficio en La herbolera.

No consideramos como base tradicional todo lo referente a las creencias paganas del pueblo vasco, a las que se alude en La herbolera y Ars Magica, en esta segunda de forma tangencial, ya que estas tesis están superadas, como hemos visto. La naturaleza de este fenómeno no tiene que ver con la supervivencia de un culto ancestral. No obstante, llama la atención que se reflejen estas cuestiones.

Para Castresana, todo se debe a variables psicológicas, aderezadas por elementos que concuerdan con los aportados por los demás textos, de carácter contextual; y relacionadas con estados alterados de conciencia, por el uso de sustancias estupefacientes. A esto último también se refiere La herbolera al hablar de las asambleas de Jentilkoba. Y para Castresana, Martínez de Lezea y Riesco, la brujería se erige en muchas ocasiones sobre la hechicería o el curanderismo. Esto no sucede en todos los casos de personas acusadas, pero en algunas ocasiones puede haber una coincidencia.

En cuanto a la caza de brujas en sí, las teorías son muchas y variadas. En todos los casos se apunta a la idea del chivo expiatorio, pues para los vecinos de las aldeas es necesario culpar a otros de las desgracias sufridas. Se añaden también condicionantes como los deseos de venganza por parte de los acusadores en La herbolera, Ars Magica, Las maléficas y Regreso a tu piel, de modo que las delaciones encarnan conflictos personales, sociales e incluso profesionales (como en el enfrentamiento entre físicos y herboleras-parteras). Cuando esto se lleva al límite, se puede hablar incluso de conspiración, como se hace sobre todo en Ars Magica, Las maléficas y Regreso a tu piel, y en menor grado en La herbolera, puesto que en este último relato se focaliza más en una cruzada contra los herejes. 
Será Azurmendi en Las maléficas quien, en referencia a una situación muy concreta que desembocaría en el suceso de las brujas de Zugarramurdi y continuaría tras el Auto de $\mathrm{Fe}$, añada, a lo ya expuesto sobre la conspiración, el afán de venganza y la búsqueda de un chivo expiatorio, otros factores: la relevancia de las acciones de Pierre de Lancre en el Labourd para prender la mecha en España; el papel determinante de los predicadores; la colaboración del abad de Urdax para que el terror llegue a esas poblaciones (por no estar de acuerdo con la desanexión de Zugarramurdi), después de abandonar la iglesia de la aldea como lugar para dirimir los conflictos vecinales, inmiscuyendo a la Inquisición; el rol de niños y adolescentes en las acusaciones; la importancia de la tratadística como aparato intelectual de la caza, etc. Se trata, por tanto, de la obra más completa y exhaustiva.

En definitiva, en cada narración se deja claro que la brujería no ha existido nunca; en todo caso, solo lo ha hecho en la mente de las personas, bien acusadores, bien reos, llegando a desbordarse de lo imaginario de tal manera que ha invadido el mundo real a través de la persecución, al materializarse en hombres y mujeres de carne y hueso.

Sintetizamos las teorías vertidas en un cuadro sinóptico para ver la confluencia entre las distintas obras:

\begin{tabular}{|c|c|c|c|c|}
\hline Retrato de una bruja & La herbolera & Ars Magica & Las maléficas & Regreso a tu piel \\
\hline \multicolumn{5}{|l|}{$\begin{array}{l}\text { Base popular muy } \\
\text { importante en la } \\
\text { brujería }\end{array}$} \\
\hline \multirow{2}{*}{$\begin{array}{l}\text { Base hechiceril } \\
\text { determinante, } \\
\text { es fácil que una } \\
\text { hechicera sea } \\
\text { considerada bruja }\end{array}$} & $\begin{array}{l}\text { Curanderismo o } \\
\text { hechicería como } \\
\text { sustrato de la } \\
\text { brujería }\end{array}$ & & & \\
\hline & $\begin{array}{l}\text { Bruja como } \\
\text { mujer sabia } \\
\text { malinterpretada por } \\
\text { la cultura dominante }\end{array}$ & $\begin{array}{l}\text { Mujer sabia o } \\
\text { practicante de la } \\
\text { magia blanca fácil } \\
\text { de confundir con la } \\
\text { bruja }\end{array}$ & & \\
\hline $\begin{array}{l}\text { Miedo al maleficio } \\
\text { como factor } \\
\text { importante }\end{array}$ & $\begin{array}{l}\text { Miedo al maleficio } \\
\text { y mal de ojo como } \\
\text { factor determinante }\end{array}$ & & & \\
\hline \multicolumn{5}{|l|}{$\begin{array}{l}\text { Uso y consumo de } \\
\text { drogas alucinógenas }\end{array}$} \\
\hline \multicolumn{5}{|l|}{$\begin{array}{l}\text { Desesperación como } \\
\text { detonante para una } \\
\text { brujería "real" }\end{array}$} \\
\hline \multicolumn{5}{|l|}{$\begin{array}{l}\text { Posibilidad de que la } \\
\text { persona implicada } \\
\text { llegue a creer que de } \\
\text { verdad es bruja }\end{array}$} \\
\hline $\begin{array}{l}\text { Marginalidad como } \\
\text { indicio de prácticas } \\
\text { brujeriles }\end{array}$ & $\begin{array}{l}\text { Marginalidad como } \\
\text { indicio de prácticas } \\
\text { brujeriles (el 'otro' } \\
\text { puede ser un } \\
\text { brujo/a) }\end{array}$ & & $\begin{array}{l}\text { Castigo a grupos } \\
\text { marginales como los } \\
\text { agotes }\end{array}$ & \\
\hline
\end{tabular}


La brujería en la narrativa histórica española... - Eva Lara Alberola

\begin{tabular}{|c|c|c|c|}
\hline \multicolumn{4}{|l|}{$\begin{array}{l}\text { Misoginia como } \\
\text { factor relevante }\end{array}$} \\
\hline \multicolumn{2}{|l|}{$\begin{array}{l}\text { Importancia de la } \\
\text { tratadística y su } \\
\text { concepción de la } \\
\text { brujería }\end{array}$} & \multicolumn{2}{|l|}{$\begin{array}{l}\text { Importancia de } \\
\text { la influencia de la } \\
\text { tratadística y su de } \\
\text { la brujería. }\end{array}$} \\
\hline \multicolumn{4}{|l|}{$\begin{array}{l}\text { Enfrentamiento } \\
\text { médicos y } \\
\text { comadronas }\end{array}$} \\
\hline \multicolumn{4}{|l|}{$\begin{array}{l}\text { Pervivencia de } \\
\text { religiones paganas }\end{array}$} \\
\hline \multicolumn{3}{|l|}{$\begin{array}{l}\text { Bruja como chivo } \\
\text { expiatorio o víctima } \\
\text { de una venganza } \\
\text { orquestada }\end{array}$} & $\begin{array}{l}\text { Brujería como } \\
\text { chivo expiatorio: } \\
\text { importancia del } \\
\text { infanticidio }\end{array}$ \\
\hline $\begin{array}{l}\text { Brujería como } \\
\text { maquinación o } \\
\text { complot para } \\
\text { eliminar lo que no } \\
\text { interesa }\end{array}$ & $\begin{array}{l}\text { Brujería como } \\
\text { conspiración por } \\
\text { parte de las esferas } \\
\text { de poder }\end{array}$ & $\begin{array}{l}\text { Brujería como } \\
\text { conspiración por } \\
\text { parte de las esferas } \\
\text { de poder: fuerza } \\
\text { inductora }\end{array}$ & \\
\hline & $\begin{array}{l}\text { Poderosa influencia } \\
\text { de los sermones, las } \\
\text { historias narradas, } \\
\text { la lectura pública } \\
\text { de cargos..., para } \\
\text { generar brotes de } \\
\text { brujería }\end{array}$ & $\begin{array}{l}\text { Poderosa influencia } \\
\text { de los sermones, } \\
\text { las historias } \\
\text { narradas, la lectura } \\
\text { pública de cargos... } \\
\text { (aleccionamiento), } \\
\text { para generar brotes } \\
\text { de brujería }\end{array}$ & $\begin{array}{l}\text { Influencia } \\
\text { determinante de } \\
\text { los sermones para } \\
\text { expandir o reactivar } \\
\text { la creencia en la } \\
\text { brujería }\end{array}$ \\
\hline & $\begin{array}{l}\text { Sugestión como } \\
\text { elemento que } \\
\text { desemboca en crisis } \\
\text { de histeria }\end{array}$ & $\begin{array}{l}\text { Sugestión como } \\
\text { elemento que } \\
\text { desemboca en crisis } \\
\text { de histeria: papel } \\
\text { crucial de niños y } \\
\text { adolescentes }\end{array}$ & $\begin{array}{l}\text { Sugestión como } \\
\text { detonante para ver } \\
\text { lo que no existe y } \\
\text { creer que todos los } \\
\text { males proceden de } \\
\text { las brujas }\end{array}$ \\
\hline & & $\begin{array}{l}\text { Relevancia de } \\
\text { las injerencias } \\
\text { externas para sacar } \\
\text { de contexto las } \\
\text { disputas vecinales } \\
\text { y convertirlas en } \\
\text { cacerías }\end{array}$ & \\
\hline & & $\begin{array}{l}\text { Persecución de } \\
\text { la brujería como } \\
\text { purga y resultado de } \\
\text { tensiones sociales, } \\
\text { que pueden reflejar } \\
\text { cambios históricos, } \\
\text { políticos, religiosos... }\end{array}$ & $\begin{array}{l}\text { Persecución de la } \\
\text { brujería como purga, } \\
\text { como resultado de } \\
\text { enfrentamiento y } \\
\text { tensiones sociales }\end{array}$ \\
\hline & & $\begin{array}{l}\text { Brujería como } \\
\text { relato, de ahí la } \\
\text { importancia de la } \\
\text { narración durante } \\
\text { los procesos y del } \\
\text { hecho de guardar } \\
\text { silencio para } \\
\text { erradicar los brotes }\end{array}$ & \\
\hline
\end{tabular}


Estas narraciones entrelazan de una manera rica y compleja, cuando tejen la historia, diferentes tesis procedentes de distintas corrientes de estudio de la brujería. El resultado es un colorido tapiz que también contribuye al análisis del fenómeno, pero desde otra perspectiva o soporte. Algunas de las muestras coinciden en ciertos ítems, pero algunos solo son desarrollados por uno de los títulos, de modo que no existe una continuidad ni coincidencia en todos los factores presentados en el cuadro. Cada autor o autora se inclina por unos condicionantes y no explota, en cambio, otros. La herbolera es el texto que más ítems combina en su argumento, seguida por Las maléficas. Existe una mayor coincidencia en entradas como el miedo al maleficio, la mujer sabia como bruja, la marginalidad como detonante, la influencia de los tratados, la trascendencia de los sermones y similares, la importancia de la sugestión, la búsqueda de un chivo expiatorio, la persecución como complot y la caza como reflejo de las tensiones sociales.

Esto nos sirve para ver qué ideas son las que más prevalecen, algunas fruto de una preconcepción errónea, como sucede al considerar a la mujer sabia como una bruja, a raíz de una mala interpretación de su papel, pues las brujas nunca se han correspondido con esa feminidad plena de dones y conocimiento, el estudio de los procesos lo demuestra; o como ocurre también en la creencia de que la brujería sería una religión pagana que ha sobrevivido.

La prevalencia de ciertos factores también tiene que ver con lo que los especialistas han demostrado a lo largo de los años, que hemos sintetizado en la introducción, y con las propias indagaciones llevadas a cabo por los escritores, que siempre se lanzan a su actividad creadora con una importante cantidad de datos contrastados.

Lo que está claro, como dice Kurt Spang, es que:

[...] también la novela histórica enseña y por tanto la lectura de estos textos sobre el pasado ayuda no solamente a conocer mejor el pasado, aunque hay autores que se limitan a ello, sino a entender mejor el presente. La historia ciertamente no se repite pero el hombre con sus virtudes y vicios, sus debilidades y aspiraciones no cambia y muchas circunstancias históricas sorprenden por su llamativo parecido con los tiempos actuales y, por tanto, pueden ofrecer paralelos o también contrastes a la hora de buscar las soluciones de conflictos del presente. (1995, p. 122)

Existe un interés generalizado por la historia, el lector se ve atraído, según Mata Indurain, no solo por los grandes hombres y acontecimientos, sino también por la historia cultural, religiosa, de las ideas o de la vida cotidiana (1995, p. 36). Ese hecho justifica también el interés de los materiales analizados, ya que quien se acerque a los mismos va a conocer ciertos hechos y vivencias que no se han explicado frecuentemente al público mayoritario, pues la información ha estado más bien en manos de los eruditos, estudiosos de la brujería, pertenecientes a distintos campos del saber. Y como una de las particularidades de estas producciones es que el 
autor no solo novela sino que también historia, se pueden hallar, como hemos visto, tesis que intentan dar cuenta de lo que pudo haber pasado y por qué, llenando los huecos presentes en los documentos historiográficos.

En cuanto a la brujería en particular, como hemos comprobado, sigue interesando a los autores y lectores contemporáneos, por el misterio que todavía la envuelve y por todas las preguntas que aún quedan sin respuesta. Asimismo, resulta un tema sumamente atractivo por todo lo que posee de intrigante, sobrecogedor y dramático. De ahí que múltiples escritores, desde la novela histórica, viertan su particular visión y sus teorías sobre este fenómeno, en un intento de resolver lo que para ellos es todavía un enigma.

Y, tras este cúmulo de teorías y el telón de fondo de ciertos periodos que quedan ciertamente bien perfilados en las distintas obras, se palpa la tragedia que vivieron tantas y tantas personas en las que se materializó el mito y que sufrieron en sus carnes los rigores de su tiempo, la persecución y la condena. $\mathrm{Y}$ al mirarse en ellos el lector puede llegar a imaginar el horror que se oculta en estos relatos, y puede hacerlo, precisamente, porque sabe que ese horror es real, no una ficción, a pesar de que se ha recreado a través de una novela.

\section{BIBLIOGRAFÍA}

Aranda Fernández-Cañadas, Eudaldo (2010). La quema de brujas de 1507. Notas en torno a un enigma histórico [en línea]. Huarte de San Juan. Geografia e Historia, n. 17, pp. 411-422. Disponible en: https://academica-e.unavarra.es/handle/2454/9200

Aranzadi, Juan (1981). Milenarismo vasco: edad de oro, etnia y nativismo. Madrid: Taurus.

Azurmendi, Mikel (2012). Las maléficas. San Sebastián: Hiria.

Azurmendi, Mikel (2013). Las brujas de Zugarramurdi: La historia del aquelarre y de la Inquisición. Córdoba: Almuzara.

Bazán, Iñaki (2007). Formas de disidencia frente a la Iglesia medieval: los herejes de Durango [en línea]. Norba. Revista de Historia, n. 20, pp. 31-51. Disponible en: https://dialnet.unirioja.es/servlet/articulo? codigo $=2866695$

Bazán, Iñaki (2011). Superstición y brujería en el Duranguesado a fines de la Edad Media: ¿Amboto 1507? [en línea]. Clío \& Crimen, n. 8, pp. 191-224. Disponible en:http://www.durangoudala.net/portalDurango/RecursosWeb/ DOCUMENTOS/1/1_5145_3.pdf

Becerra, Daniel (2004). Ungüentos, transformaciones y vuelos. Brujería y psicoactivos de la Antigüedad como antecedente de la brujería en la Edad Media [en línea]. Bolskan, n. 21, pp. 121-128. Disponible en: http://revistas.iea.es/index.php/BLK/ article/view/442 
Revista de Humanidades, 37 (2019).p. 35-72. ISSN 1130-5029

Bologne, Jean Claude (1997). De la antorcha a la hoguera. Madrid: Anaya \& Mario Muchnick.

Caro Baroja, Julio (1995 [1966]). Las brujas y su mundo. Madrid: Alianza.

Cáseda Teresa, Jesús Fernando (2007). Brujas e Inquisición en Calahorra: una historia poco conocida [en línea]. Kalakorikos, n. 12, pp. 301-310. Disponible en: https:// dialnet.unirioja.es/servlet/articulo?codigo $=2484128$

Castel, Pau (2013). Orígens i evolució de la cacera de bruixes a Catalunya (segles XV$X V I)$, tesis doctoral. Barcelona: Universitat de Barcelona.

Castresana, Luis de (1973 [1970]). Retrato de una bruja. Barcelona: Círculo de Lectores.

Clark, Stuart (2004). Brujería e imaginación histórica. Nuevas interpretaciones de la demonología en la Edad Moderna. En Tausiet, María y Amelang, James (eds.). El diablo en la Edad Moderna. Madrid: Marcial Pons, pp. 21-44.

Cohn, Norman (1980 [1975]). Los demonios familiares en Europa. Madrid: Alianza.

Delpech, François (1993). La marque des sorcières: logique(s) de la stigmatisation diabolique. En Jacquin, N. y Préaud, M. (eds.). Le sabbat des sorciers, XV-XVIII siècles. París: Editions Jérôme Millon, pp. 347-368.

Díaz-Rosales, Juan de Dios (2011). Mitos y ciencia: Brujería, herbolaria y autosugestión [en línea]. Boletín mexicano de historia y filosofía de la medicina, n. 14.1, pp. 2829. Disponible en: http://www.medigraphic.com/pdfs/bmhfm/hf-2011/hf111g.pdf

Donovan, Frank (1978). Historia de la brujería. Madrid: Alianza.

Faggin, Giuseppe (1959). Le streghe. Milano: Longanesi \& C.

Fonseca, Luis de (1611). Relación summaria del auto de la fe... Burgos: Juan Bautista Varesio.

Foucault, Michel (1999). Los anormales: Curso en el Collége de France (1974-1975). Buenos Aires: Fondo de Cultura Económica.

Gabás, Luz (2014). Regreso a tu piel. Barcelona: Planeta.

Gari Lacruz, Ángel (1987). El uso de drogas en la brujería y en algunos relatos de magia, XV Jornadas de Socidrogalcohol. Zaragoza: Socidrogalcohol.

Gari Lacruz, Ángel (2010). La brujería en los Pirineos (siglos XIII-XVII). Aproximación a su historia [en línea]. Cuadernos de Etnología y Etnografía de Navarra (CEEN), n. 85, pp. 317-354. Disponible en: https://dialnet.unirioja.es/servlet/ articulo? codigo $=3392731$

Ginzburg, Carlo (2004). Ecstasies. Deciphering the witches'sabbat, Chicago. Chicago: University Press.

Henningsen, Gustav (1983 [1980]). El abogado de las brujas: Brujería vasca e Inquisición española. Madrid: Alianza.

Jiménez del Oso, Fernando (1995). Brujas. Las amantes del diablo. Madrid: Anaya. 
La brujería en la narrativa histórica española... - Eva Lara Alberola

Koning, Frederick (1975). Historia del satanismo. Barcelona: Bruguera.

Lara Alberola, Eva (2010). Hechiceras y brujas en la literatura española de los Siglos de Oro. Valencia: Universidad de Valencia.

Lara Alberola, Eva (2014). Retrato de una bruja de Luis de Castresana (1970). Del siglo $\mathrm{XX}$ al siglo XVII: una nueva mirada sobre la brujería [en línea]. eHumanista, $\mathrm{n}$. 26, pp. 287-327. Disponible en: http://www.ehumanista.ucsb.edu/sites/secure.lsit. ucsb.edu.span.d7_eh/files/sitefiles/ehumanista/volume26/ehum26.14.alberola.pdf

Levack, Bryan P. (1994). La bruja. En Villari, R. (ed.). El hombre barroco. Madrid: Alianza, pp. 291-318.

Levack, Brian P. (1995). La caza de brujas en la Europa moderna. Madrid: Alianza.

López Ibor, Juan José (1976). ¿Cómo se fabrica una bruja? Barcelona: Dopesa.

Lowenthal, David (1985). The Past is a Foreign Country. Cambridge: Cambridge University Press.

Lukács, Georg (1966). La novela histórica. México: Era.

Martínez de Lezea, Toti (2006 [2000]). La herbolera. Madrid: Maeva.

Mara Indurain, Carlos (1995). Retrospectiva sobre la evolución de la novela histórica. En Spang, Kurt; Arellano, Ignacio y Mata, Carlos (eds.). La novela histórica. Teoría y comentarios. Pamplona: Eunsa, pp. 13-63.

Mongastón, Juan de (1997). Relación de las personas que salieron al Auto de Fe... En Marcos, Manuel A. y Riesco, Hipólito B. (eds.). Discurso acerca de los cuentos de las brujas. León: Secretariado de publicaciones de la Universidad de León, pp. 157-181.

Montaner, Alberto (2014). El paradigma satánico de la brujería o el diablo como recurso epistémico [en línea]. eHumanista, n. 27, pp. 116-132. Disponible en: http:// www.ehumanista.ucsb.edu/sites/secure.1sit.ucsb.edu.span.d7 eh/files/sitefiles/ ehumanista/volume26/ehum26.6.montaner.pdf

Montaner, Alberto; Lara, Eva (2014). Magia, hechicería, brujería: deslinde de conceptos. En Lara, Eva y Montaner, Alberto (eds.). Señales, portentos y demonios: La magia en la literatura y la cultura españolas del Renacimiento. Salamanca: Semyr, pp. 33-184.

Muchembled, Robert (1990). Satanic Myths and Cultural Reality. En Ankarloo, Bengt y Henningsen, Gustav (eds.). Early Modern European Witchcraft. Oxford: Oxford University Press, pp. 139-160.

Muchembled, Roberto (2004). Historia del Diablo. Madrid: Cátedra.

Murray, Margaret (1978 [1921]). El culto de la brujería en Europa Occidental. Barcelona: Labor.

Murray, Margaret (1985 [1931]). El dios de los brujos. México: Fondo de Cultura Económica. 
Revista de Humanidades, 37 (2019).p. 35-72. ISSN 1130-5029

Ramón, Emilio (2007). De las olimpiadas de Barcelona a la ley de memoria histórica: la re-visión de la historia en la novela histórica española. Murcia: Nausícaä.

Reis, Carlos (1998). Diálogos com José Saramago. Alfragide: Caminho.

Reguera, Iñaki (2005). La inquisición en el País Vasco. El periodo fundacional [en línea]. Clío \& Crimen, n. 2, pp. 237-255. Disponible en: http://www.durango-udala.eus/ portalDurango/RecursosWeb/DOCUMENTOS/1/0_449_1.pdf

Reguera, Iñaki (2012). La brujería vasca en la Edad Moderna: aquelarres, hechicería y curanderismo. RIEV, n. 9, Usunáriz, Jesús $\mathrm{M}^{\mathrm{a}}$ (ed.). Akelarre: la caza de brujas en el Pirineo (siglos XIII-XIX), pp. 240-283.

Riesco, Nerea (2007). Ars Magica. Barcelona: Grijalbo.

Rowland, Robert (1998). Fantasticall and Devilishe Persons: European Witch-beliefs in Comparative Perspective. En Ankarloo, Bengt y Henningsen, Gustav (eds.). Early Modern European Witchcraft. Oxford: Oxford University Press, pp. 161-190.

Sánchez Ortega, Ma Helena (2004). Ese viejo diablo llamado amor. La magia amorosa en la España moderna. Madrid: UNED.

Serra i Rotés, Rosa (1994). Bruixes, més que bruixes, les berguedanes! [en línea]. L’Erol. Revista cultural del Berguedà, n. 46, pp. 15-21. Disponible en: http://www.raco. cat/index.php/Erol/article/view/172218

Spang, Kurt (1995). Apuntes para una definición de la novela histórica. En Spang, Kurt; Arellano, Ignacio y Mata, Carlos (eds.). La novela histórica. Pamplona: Eunsa, pp. $65-114$.

Sprenger, Jacobo; Institoris, Enrique (2004 [1486]). Malleus Maleficarum. Valladolid: Maxtor,

Stewart, Pamela J. y Strathern, Andrew (2008). Brujería, hechicería, rumores y habladurías. Madrid: Akal.

Tausiet, María (1997). Comadronas-brujas en Aragón en la Edad Moderna: mito y realidad [en línea]. Manuscrits, n. 15, pp. 377-392. Disponible en: https://ddd.uab. cat/pub/manuscrits/02132397n15/02132397n15p377.pdf

Tausiet, María (1998). Brujería y metáfora: el infanticidio y sus traducciones en Aragón (s. XVI-XVII) [en línea]. Temas de antropología aragonesa, n. 8. Zaragoza: Instituto Aragonés de Antropología, pp. 61-83. Disponible en: https://antropologiaaragonesa. org/pdf/temas/8.02_Brujeria.pdf

Tausiet, María (2004a). Avatares del mal: el diablo en las brujas. En Tausiet, María y Amelang, James (eds.). El diablo en la Edad Moderna. Madrid: Marcial Pons, pp. 45-66.

Tausiet, María (2004b [2000]). Ponzoña en los ojos. Brujería y superstición en Aragón en el siglo XVI. Madrid: Turner.

Torquemada, Antonio de (2000 [1570]). Jardín de flores curiosas. San Sebastián: Roger Editor. 
La brujería en la narrativa histórica española... - Eva Lara Alberola

Uceda, Julia (1992). Criaturas senderianas (variaciones sobre una obra abierta). Alazet, n. 4, pp. 187-214.

Usunáriz Garayoa. Jesús M $\mathrm{M}^{\mathrm{a}}$ (2012). La caza de brujas en la Navarra moderna (siglos XVI-XVII). RIEV, n. 9, Jesús $\mathrm{M}^{\mathrm{a}}$ Usunáriz (ed.). Akelarre: la caza de brujas en el Pirineo (siglos XIII-XIX). Homenaje al profesor Gustav Henningsen, pp. 306-350.

Val, $\mathrm{M}^{\mathrm{a}}$ Isabel del (2012). Al borde de la exclusión social. Algunos ejemplos femeninos [en línea]. Clío \& Crimen, n. 9, pp. 15-36. Disponible en: https://www.durangoudala.net/portalDurango/RecursosWeb/DOCUMENTOS/1/6_6328_3.pdf 